\title{
Updating the Cornell Net Carbohydrate and Protein System feed library and analyzing model sensitivity to feed inputs
}

\author{
R. J. Higgs, L. E. Chase, D. A. Ross, and M. E. Van Amburgh ${ }^{1}$ \\ Department of Animal Science, Cornell University, Ithaca, NY 14853
}

\begin{abstract}
The Cornell Net Carbohydrate and Protein System (CNCPS) is a nutritional model that evaluates the environmental and nutritional resources available in an animal production system and enables the formulation of diets that closely match the predicted animal requirements. The model includes a library of approximately 800 different ingredients that provide the platform for describing the chemical composition of the diet to be formulated. Each feed in the feed library was evaluated against data from 2 commercial laboratories and updated when required to enable more precise predictions of dietary energy and protein supply. A multistep approach was developed to predict uncertain values using linear regression, matrix regression, and optimization. The approach provided an efficient and repeatable way of evaluating and refining the composition of a large number of different feeds against commercially generated data similar to that used by CNCPS users on a daily basis. The protein A fraction in the CNCPS, formerly classified as nonprotein nitrogen, was reclassified to ammonia for ease and availability of analysis and to provide a better prediction of the contribution of metabolizable protein from free AA and small peptides. Amino acid profiles were updated using contemporary data sets and now represent the profile of AA in the whole feed rather than the insoluble residue. Model sensitivity to variation in feed library inputs was investigated using Monte Carlo simulation. Results showed the prediction of metabolizable energy was most sensitive to variation in feed chemistry and fractionation, whereas predictions of metabolizable protein were most sensitive to variation in digestion rates. Regular laboratory analysis of samples taken on-farm remains the recommended approach to characterizing the chemical components of feeds in a ration. However, updates to
\end{abstract}

Received January 24, 2015.

Accepted May 25, 2015.

${ }^{1}$ Corresponding author: mev1@cornell.edu the CNCPS feed library provide a database of ingredients that are consistent with current feed chemistry information and laboratory methods and can be used as a platform to formulate rations and improve the description of biology within the model.

Key words: feed composition, Cornell Net Carbohydrate and Protein System, modeling, methods, sensitivity

\section{INTRODUCTION}

Obtaining useful outputs from any biological model is very dependent on the quality of the information being used to perform a simulation (Haefner, 2005). The feed library in the Cornell Net Carbohydrate and Protein System (CNCPS) contains information not routinely available from commercial laboratories such as AA profiles, FA profiles, digestion rates $(\mathbf{k d})$, and intestinal digestibilities (Tylutki et al., 2008). The feed library also provides commonly analyzed fractions that can be used as they are or updated by the user. Correct estimation of these chemical components is critical in enabling the CNCPS to best predict the $\mathrm{ME}, \mathrm{MP}$, and other specific nutrients available from a given ration (Offner and Sauvant, 2004; Lanzas et al., 2007a,b). Regular laboratory analysis of feeds will reduce the variation in model inputs to that derived from the sampling process, sample handling, preparation, and the variation of the assay itself (Hall and Mertens, 2012). However, in some situations, this is not possible and feed library values have to be relied on. In other situations, feed compositions are very consistent, meaning library values provide a reasonable estimation without laboratory analysis. The CNCPS feed library consists of approximately 800 ingredients, including forages, concentrates, vitamins, minerals, and commercial products, and serves as the reference database for describing the chemical composition of a diet. The origin of the feed library is from the work of Van Soest (1994, 2015), Sniffen et al. (1992), and related publications. The addition of AA to the feed library began 
with the publication of O'Connor et al. (1993). Many of the feed ingredients have been updated since that time, using data from more contemporary sources such as the National Research Council publications and other commercial feed additions through the CPM Dairy (University of Pennsylvania, Kennett Square, PA) effort, but not in a systematic or comprehensive manner. The objective of the current study was to evaluate and revise the CNCPS feed library to ensure that it is consistent with values being generated and used as inputs from commercial laboratories. A multistep approach was designed and used to combine current feed library information with new information and predict uncertain values. The intended methods for analyzing each major chemical component for use in the CNCPS are reported, as well as a sensitivity analysis of model outputs to variation in feed library inputs. An evaluation of model outputs and sensitivity relative to animal data is provided in a companion paper (Van Amburgh et al., 2015).

\section{MATERIALS AND METHODS}

\section{Feed Chemistry}

The chemical components considered in our study were those routinely analyzed by commercial laboratories and required by the CNCPS for evaluation and formulation of nutrient adequacy and supply. These include DM, CP, soluble protein (SP), ammonia, acid detergent-insoluble CP (ADICP), neutral detergentinsoluble CP (NDICP), acetic acid, propionic acid, butyric acid, lactic acid, other organic acids, water-soluble carbohydrates (WSC), starch, ADF, NDF, lignin, ash, ether extract (EE), and soluble fiber. Amino acids were also reviewed and updated. A list of the expected analytical procedures for measuring each chemical component and the units required by the CNCPS v6.5 are described in Table 1. Fractionation of chemical components from Table 1 into the pool structure of the CNCPS are described by Tylutki et al. (2008) and summarized in Table 2.

\section{Calculation Procedure}

To complete the analysis, data sets were provided by 2 commercial laboratories (Cumberland Valley Analytical Services Inc., Maugansville, MD, and Dairy One Cooperative Inc., Ithaca, NY). The compiled data set included 90 different ingredients and $>100,000$ individual samples. Additional means and standard deviations (SD) of individual feeds were sourced from the laboratory websites. The online resource for both laboratories includes $>10$ yr of data and an extensive collection of different ingredients. Each feed was evaluated for internal consistency and consistency against laboratory data. Internal consistency required each feed to adhere to the fractionation scheme summarized in Table 2. Briefly, equation [1] (Table 2) provides the relationship between carbohydrates (CHO), CP, EE, and ash. Carbohydrates are characterized as NDF, acetic, propionic, butyric, isobutyric, lactic, and other organic acids, WSC, starch, and soluble fiber. From equations [1], [4], and [5] in Table 2, equation [16] can be derived for the $j$ th feed in the library:

$$
\begin{gathered}
100=\mathrm{CP}_{j}+\mathrm{EE}_{j}+\operatorname{ash}_{j}+\mathrm{NDF}_{j}+\text { acetic }_{j} \\
+\operatorname{propionic}_{j}+\text { isobutyric }_{j}+\text { lactic }_{j}++ \text { other organic } \\
\text { acids }_{j}+\mathrm{WSC}_{j}+\operatorname{starch}_{j}+\text { soluble fiber }_{j} \text { [16] }
\end{gathered}
$$

Soluble fiber (CB2) is calculated in the CNCPS by difference (equation [5]). This means any error in the estimation of the CA1 (volatile fatty acids), CA2 (lactic acid), CA3 (other organic acids), CA4 (WSC)], or CB1 (starch) fractions will result in an over- or underestimation of soluble fiber. Also, error in the estimation of CP, EE, ash, or NDF will cause error in soluble fiber through the calculation of $\mathrm{CHO}$ (equation [1]) and the subsequent calculation of NFC (equation [4]). Other components, such as alcohols, are also included in soluble fiber within the current structure of the model. Overestimation of components in equation [16] can cause a situation where soluble fiber is forced to 0 and the sum of the equation is greater than $100 \%$ DM, which, theoretically, is chemically impossible. Feeds that did not adhere to the assumptions of equation [16] were updated. This rule can be problematic when the $\mathrm{N}$ content of protein deviates from $16 \%$, in which a factor of 6.25 was used to convert the amount of $\mathrm{N}$ to an equivalent weight of protein (Van Soest, 1994). The mass of all proteins in the CNCPS are calculated as N $\times 6.25$ despite the proper factor varying according to feed type (Van Soest, 1994). Therefore, for feeds high in NPN (urea, ammonium salts), equation 16 was allowed to exceed $100 \%$ DM. This is a legacy issue with the CNCPS and other formulation systems and would require considerable recoding to an $\mathrm{N}$ basis to overcome. However, future versions of the model will address this problem. Likewise, NDF in the data sets provided were not ash-corrected as recommended in Table 1, as these data were not available at time the analysis was conducted. The distributions of corn silage ash and NDF are in Figure 1. Both distributions are skewed to the left, which in the case of NDF, indicates ash contamination (Mertens, 2002). Over-estimation of NDF through 


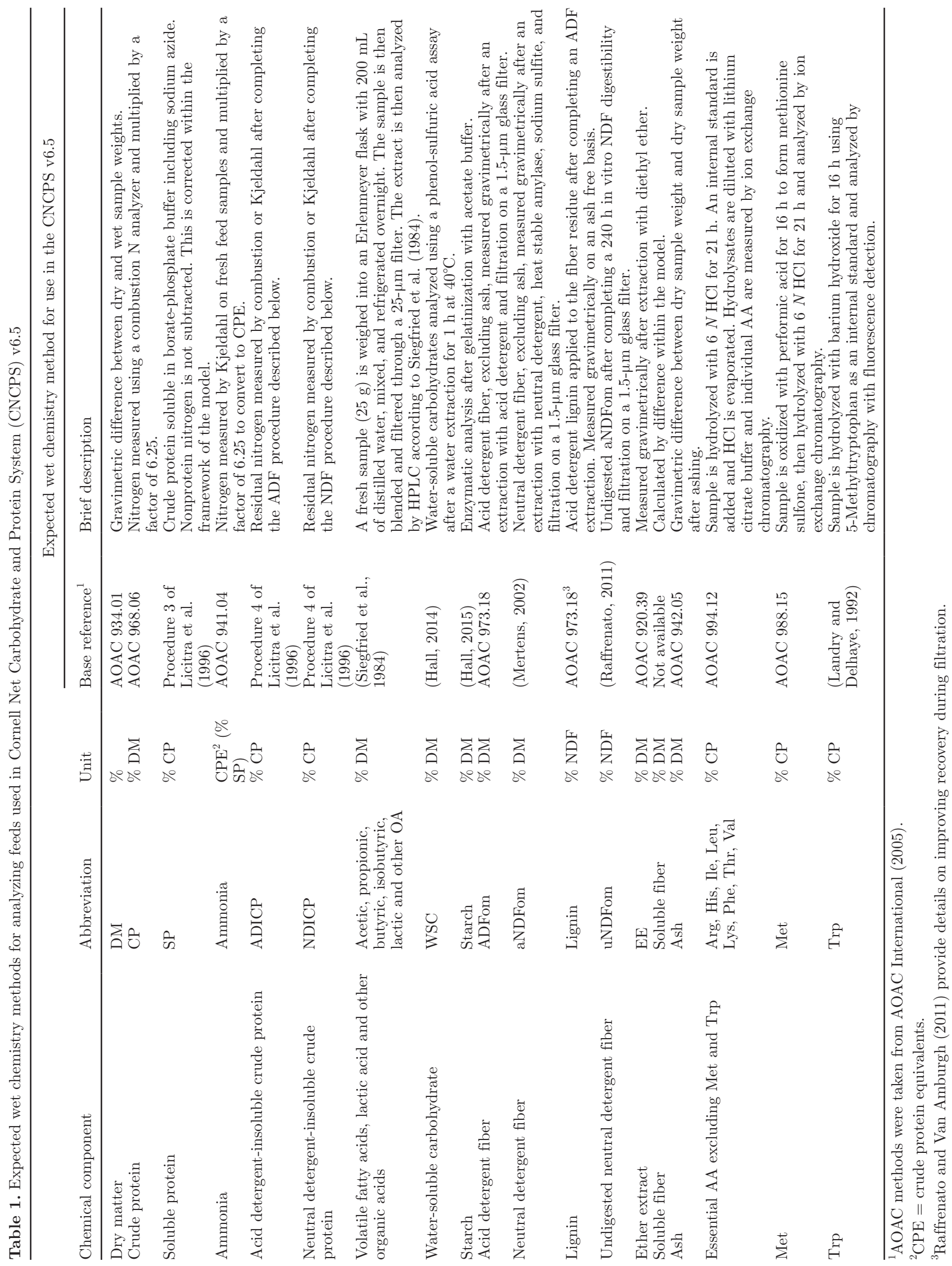


Table 2. Equations used by the Cornell Net Carbohydrate and Protein System (CNCPS) to calculate carbohydrate and protein fractions

\begin{tabular}{|c|c|c|c|}
\hline Fraction $^{1}$ & Description & Equation $^{2,3}$ & $\begin{array}{l}\text { Equation } \\
\text { no. }\end{array}$ \\
\hline $\mathrm{CHO} j$ & Carbohydrates & $100-\mathrm{CP} j-\mathrm{EE} j-\operatorname{Ash} j$ & {$[1]$} \\
\hline $\mathrm{CC} j$ & Indigestible fiber & $(\operatorname{aNDFom} j \times(\operatorname{Lignin} j \times$ aNDFom $j) \times 2.4) / 100$ or, aNDFom $j \times$ uNDFom $j$ & {$[2]$} \\
\hline $\mathrm{NFC} j$ & Nonfiber $\mathrm{CHO}$ & $\mathrm{CHO} j-\operatorname{aNDFom} j$ & {$[4]$} \\
\hline $\mathrm{CB} 2 j$ & Soluble fiber & $\mathrm{NFC} j-\mathrm{CA} 1 j-\mathrm{CA} 2 j-\mathrm{CA} 3 j-\mathrm{CA} 4 j-\mathrm{CB} 1 j$ & {$[5]$} \\
\hline CA1 $j$ & Volatile fatty acids & Acetic $j+$ Propionic $j+$ (Butyric + Isobutyric $) j$ & [6] \\
\hline $\mathrm{CA} 4 j$ & WSC & WSC $j$ & [9] \\
\hline $\mathrm{CB} 1 j$ & Starch & Starch $j$ & [10] \\
\hline $\mathrm{PA} 1 j^{4}$ & Ammonia & Ammonia $j \times(\mathrm{SP} j / 100) \times(\mathrm{CP} j / 100)$ & {$[11]$} \\
\hline $\mathrm{PA} 2 j$ & Soluble true protein & $\mathrm{SP} j \times \mathrm{CP} j / 100-\mathrm{PA} 1 j$ & {$[12]$} \\
\hline $\mathrm{PB} 1 j$ & Insoluble true protein & $\mathrm{CP} j-(\mathrm{PA} 1 j-\mathrm{PA} 2 j-\mathrm{PB} 2 j-\mathrm{PC} j)$ & [13] \\
\hline $\mathrm{PB} 2 j$ & Fiber-bound protein & $(\mathrm{NDICP} j-\operatorname{ADICP} j) \times \mathrm{CP} j / 100$ & {$[14]$} \\
\hline $\mathrm{PC} j$ & Indigestible protein & $\mathrm{ADICP} j \times \mathrm{CP} j / 100$ & {$[15]$} \\
\hline
\end{tabular}

${ }^{1}$ Subscript $j$ means the $j$ th feed in the library.

${ }^{2} \mathrm{EE}=$ ether extract; WSC $=$ water-soluble carbohydrates; $\mathrm{SP}=$ soluble protein; $\mathrm{ADICP}=$ acid detergent-insoluble $\mathrm{CP} ; \mathrm{NDICP}=$ neutral detergent-insoluble CP; aNDFom = NDF assay with amylase, sodium sulfite and ash correction; uNDFom $=$ undigested NDFom after a 240-h in vitro fermentation and ash correction.

${ }^{3}$ Chemical components are expressed as percent DM except: $\mathrm{SP}=\% \mathrm{CP} ; \mathrm{ADICP}=\% \mathrm{CP} ; \mathrm{NDICP}=\% \mathrm{CP} ;$ ammonia $=\% \mathrm{SP} ;$ lignin $=\%$ $\mathrm{NDF} ; \mathrm{uNDFom}=$ unavailable aNDFom, $\%$ NDF.

${ }^{4}$ Previous versions of the CNCPS feed library use NPN for the PA1 fraction. This has been replaced with ammonia.

ash contamination could also influence estimates of kd. Commercial laboratories have addressed this issue through determination of NDF digestibility on an OM basis. Using NDF assay with amylase, sodium sulfite and ash correction (aNDFom) in future updates of the library is recommended to remove variance associated with ash contamination. Evaluation against laboratory data compared each individual feed in the feed library to the mean and SD of the corresponding feed in the databases available from the commercial laboratories. Each component within each feed was required to fall within $1 \mathrm{SD}$ of the mean value from the laboratory data
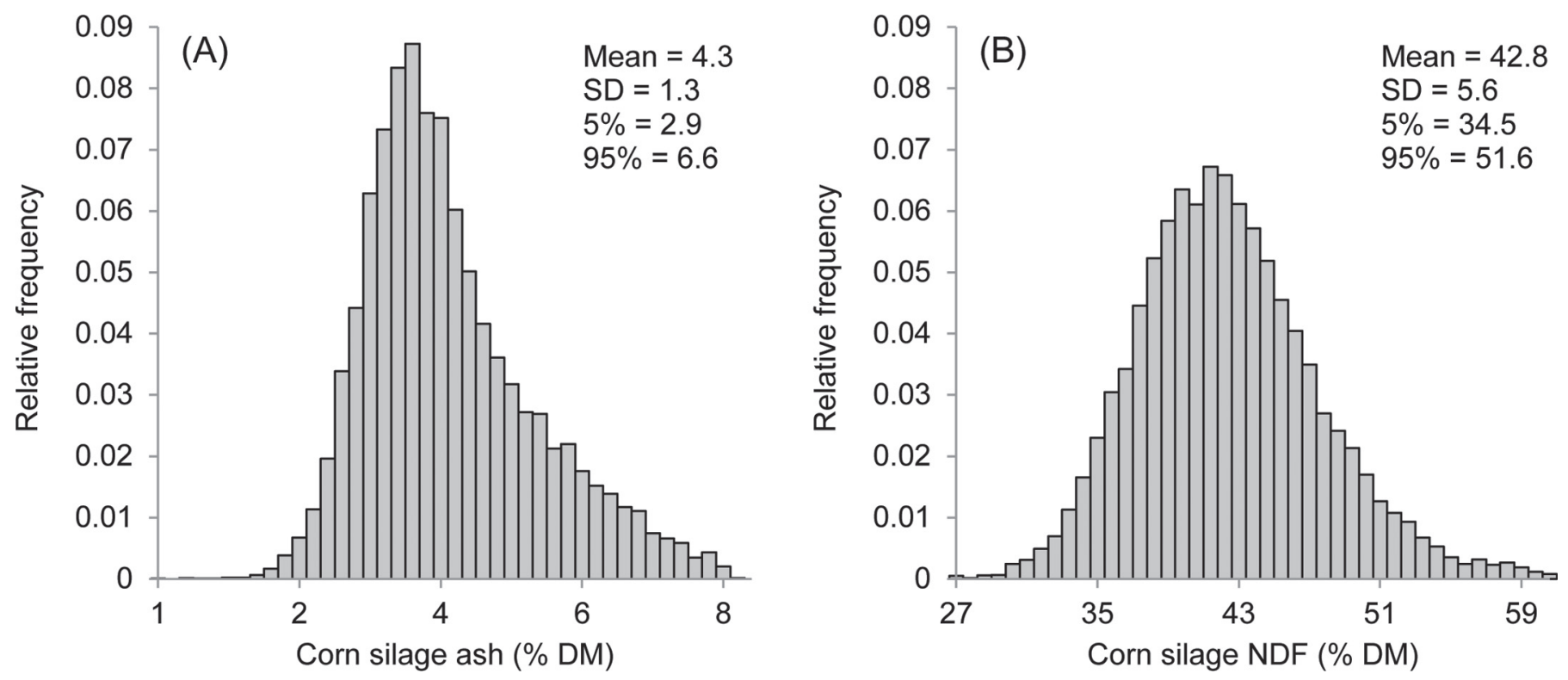

Figure 1. Frequency distributions for corn silage ash (A) and NDF (B) generated using commercial laboratory data sets $(\mathrm{n}=21,000$; Cumberland Valley Analytical Services Inc., Maugansville, MD, and Dairy One Cooperative Inc., Ithaca, NY). 
Table 3. Predicting chemical components ${ }^{1}$ of feeds using simple and multiple linear regression $\left(Y=A+B X_{1}+C X_{2}+D X_{3}\right)$

\begin{tabular}{|c|c|c|c|c|c|c|c|c|c|c|}
\hline Feed name & $Y$ & $X_{1}$ & $X_{2}$ & $X_{3}$ & $A$ & $B$ & $C$ & $D$ & $\mathrm{RMSE}^{2}$ & $\mathrm{R}^{2}$ \\
\hline Corn silage & $\mathrm{ADF}$ & $\mathrm{NDF}$ & & & -3.67 & 0.68 & & & 1.28 & 0.89 \\
\hline Corn silage & Starch & $\mathrm{NDF}$ & $\mathrm{CP}$ & & 96.18 & -1.18 & -1.62 & & 2.6 & 0.87 \\
\hline Fresh grass (low NDF) & $\mathrm{ADF}$ & $\mathrm{NDF}$ & Lignin & $\mathrm{CP}$ & 5.84 & 0.45 & 0.51 & -0.17 & 2.11 & 0.83 \\
\hline Fresh legume & $\mathrm{ADF}$ & $\mathrm{NDF}$ & Lignin & & -6.31 & 0.69 & 0.52 & & 1.53 & 0.88 \\
\hline Grass hay & $\mathrm{ADF}$ & $\mathrm{NDF}$ & & & 3.57 & 0.57 & & & 3.21 & 0.69 \\
\hline
\end{tabular}

${ }^{1}$ Expressed as percent DM, except lignin, which is expressed as percent NDF.

${ }^{2} \mathrm{RMSE}=$ root mean square error.

set, or the entire feed would be updated. The calculation procedure consisted of 4 steps.

\section{Step 1: Setting Descriptive Values}

Chemical components used to differentiate different forms of the same feed were held constant during the recalculation process. The CNCPS has multiple options for many of the feeds in the feed library to give users the flexibility to pick the feed that best matches what they are feeding on the farm. For example, the feed library has 24 different options for processed corn silage that are differentiated on the basis of DM and NDF. Therefore, in this example, DM and NDF were maintained as they were in the original library whereas other components were recalculated.

\section{Step 2: Linear Regression}

In the second step, the data set provided was used to establish relationships among feed components using linear regression $\left(Y=A+B X_{1}+C X_{2}+D X_{3}\right)$. Regression was used if components could be robustly predicted by other components within a feed $\left(\mathrm{R}^{2}>\right.$ $0.65)$. Regression equations were derived using the general linear modeling function in SAS (2010). Examples of some of the regression equations used are in Table 3.

\section{Step 3: Matrix Regression}

In the third step, factors that could not be predicted using standard linear regression were calculated using a matrix of regression coefficients derived from data generated using a Monte Carlo simulation (Law and Kelton, 2000). The Monte Carlo simulation was completed using @Risk version 5.7 (Palisade Corporation, Ithaca, NY). To complete the analysis, probability density functions were fit to each chemical component of each feed using the data provided by the commercial laboratories and the distribution fitting function in @
Risk (Palisade, 2010a). A detailed description of the distributions used can be found in Palisade (2010a). Distributions were ranked on how well they fit the input data using the Chi-squared goodness of fit statistic. Equiprobable bins were used to adjust bin size in the Chi-square calculation to contain an equal amount of probability (Law and Kelton, 2000). The distribution with the lowest Chi-square was assigned to each component. Examples of the distribution derived for each chemical component for a range of feeds are in Table 4.

Components within each feed were then correlated with each other using laboratory data and the "define correlation" function in @Risk (Palisade, 2010a). If components were not correlated, they would change randomly relative to each other during the Monte Carlo simulation. Correlating the components meant that for each iteration, components changed in tandem relative to each other with the magnitude of the change depending on the assigned correlation coefficient (Law and Kelton, 2000). Spearman rank order correlations were used which determine the rank of a component relative to another by its position within the min-max range of possible values. Rank correlations can range between -1 and 1 , with a value of 1 meaning components are $100 \%$ positively correlated, -1 meaning components are $100 \%$ negatively correlated, and 0 meaning no relationship exists between components (Law and Kelton, 2000). The correlation coefficients derived for a range of feeds used in the Monte Carlo simulation are in Table 5.

Once the probability density functions had been fit to each component, and components within each feed correlated, a Monte Carlo simulation was performed with 30,000 iterations. Various sampling techniques are available in @Risk to draw the sample from the probability density function (Palisade, 2010a). The Latin Hypercube technique was used to divide the distribution into intervals of equal probability and then randomly take a sample from each interval, forcing the simulation to represent the whole distribution (Shapiro, 2003). The raw data from the simulation was then used 
Table 4. Mean, SD, distribution, and distribution parameters for each chemical component of each feed used to perform Monte Carlo simulations

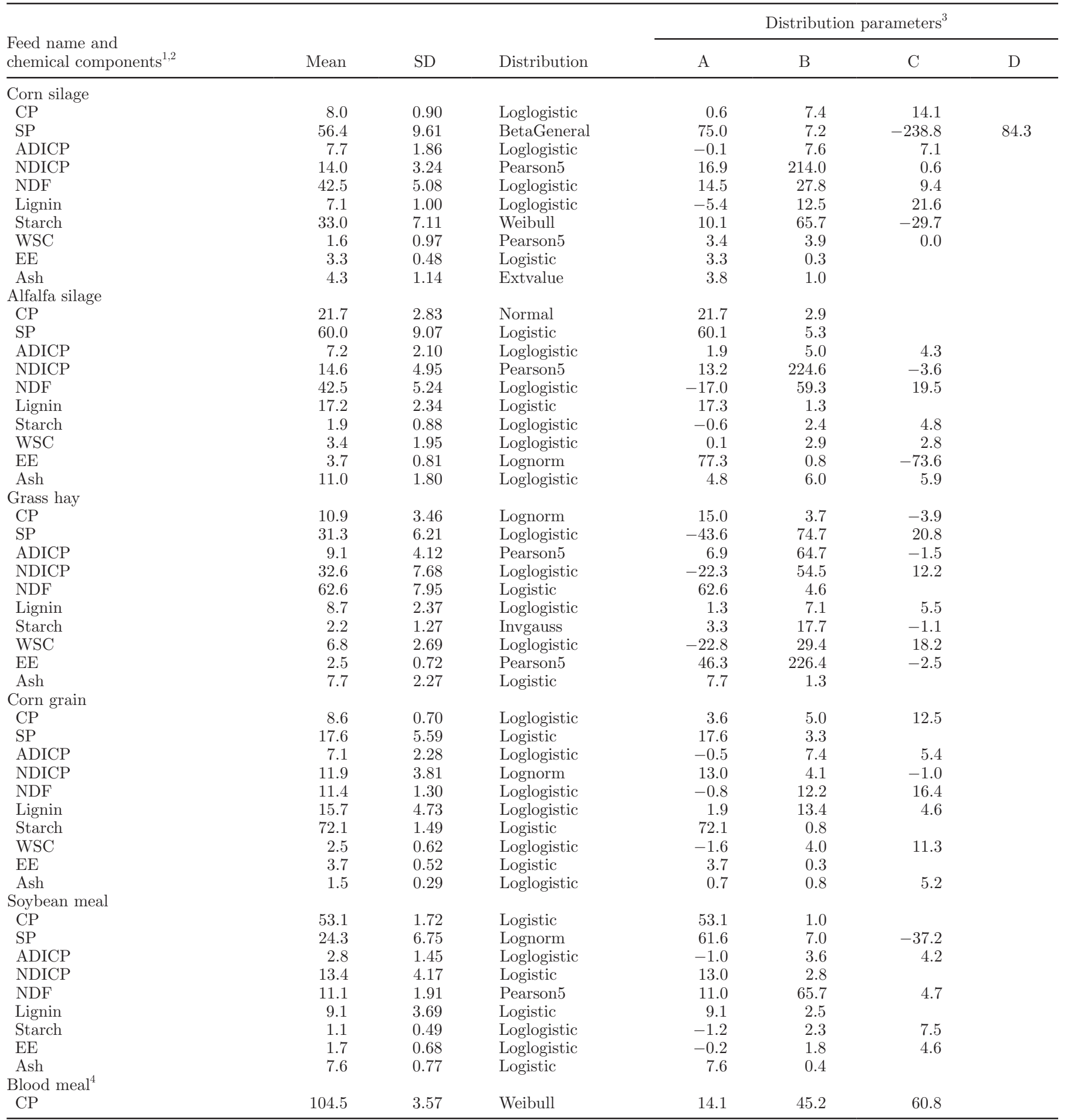

${ }^{1} \mathrm{WSC}=$ water-soluble carbohydrates; $\mathrm{SP}=$ soluble protein; ADICP $=$ acid detergent-insoluble $\mathrm{CP} ; \mathrm{NDICP}=$ neutral detergent-insoluble $\mathrm{CP}$; $\mathrm{EE}=$ ether extract.

${ }^{2}$ Chemical components are expressed as $\%$ of DM except: $\mathrm{SP}=\%$ of $\mathrm{CP}$; $\mathrm{ADICP}=\%$ of $\mathrm{CP}$; NDICP $=\%$ of $\mathrm{CP}$; Lignin $=\%$ of $\mathrm{NDF}$.

${ }^{3} \mathrm{~A}, \mathrm{~B}, \mathrm{C}$ and $\mathrm{D}$ are the parameters that define the characteristics of each distribution: BetaGeneral, $\mathrm{A}=\mathrm{Shape}, \mathrm{B}=\mathrm{Shape}, \mathrm{C}=\mathrm{Min}$ value, $\mathrm{D}=$ Max value; ExtValue, $\mathrm{A}=$ Location, $\mathrm{B}=$ Scale; Invgauss, $\mathrm{A}=$ Mean, $\mathrm{B}=$ Variance, $\mathrm{C}=$ Shift; Logistic, $\mathrm{A}=\mathrm{Location}, \mathrm{B}=$ Scale, Loglogistic, $\mathrm{A}=$ Location, $\mathrm{B}=$ Scale, $\mathrm{C}=$ Shape; Lognorm, $\mathrm{A}=$ Mean, $\mathrm{B}=$ Variance, $\mathrm{C}=$ Shift; Normal, $\mathrm{A}=\mathrm{Mean}, \mathrm{B}=\mathrm{SD} ; \mathrm{Pearson} 5, \mathrm{~A}=\mathrm{Shape}, \mathrm{B}$ $=$ Scale, $\mathrm{C}=$ Shift; Weibull, $\mathrm{A}=$ Shape, $\mathrm{B}=$ Scale, $\mathrm{C}=$ Shift.

${ }^{4}$ Blood meal CP can be $>100 \% \mathrm{DM}$ if nitrogenous components are $>16 \% \mathrm{~N}$. 
Table 5. Spearman rank correlation coefficients for the chemical components of feeds used to perform Monte Carlo simulations ${ }^{1,2}$

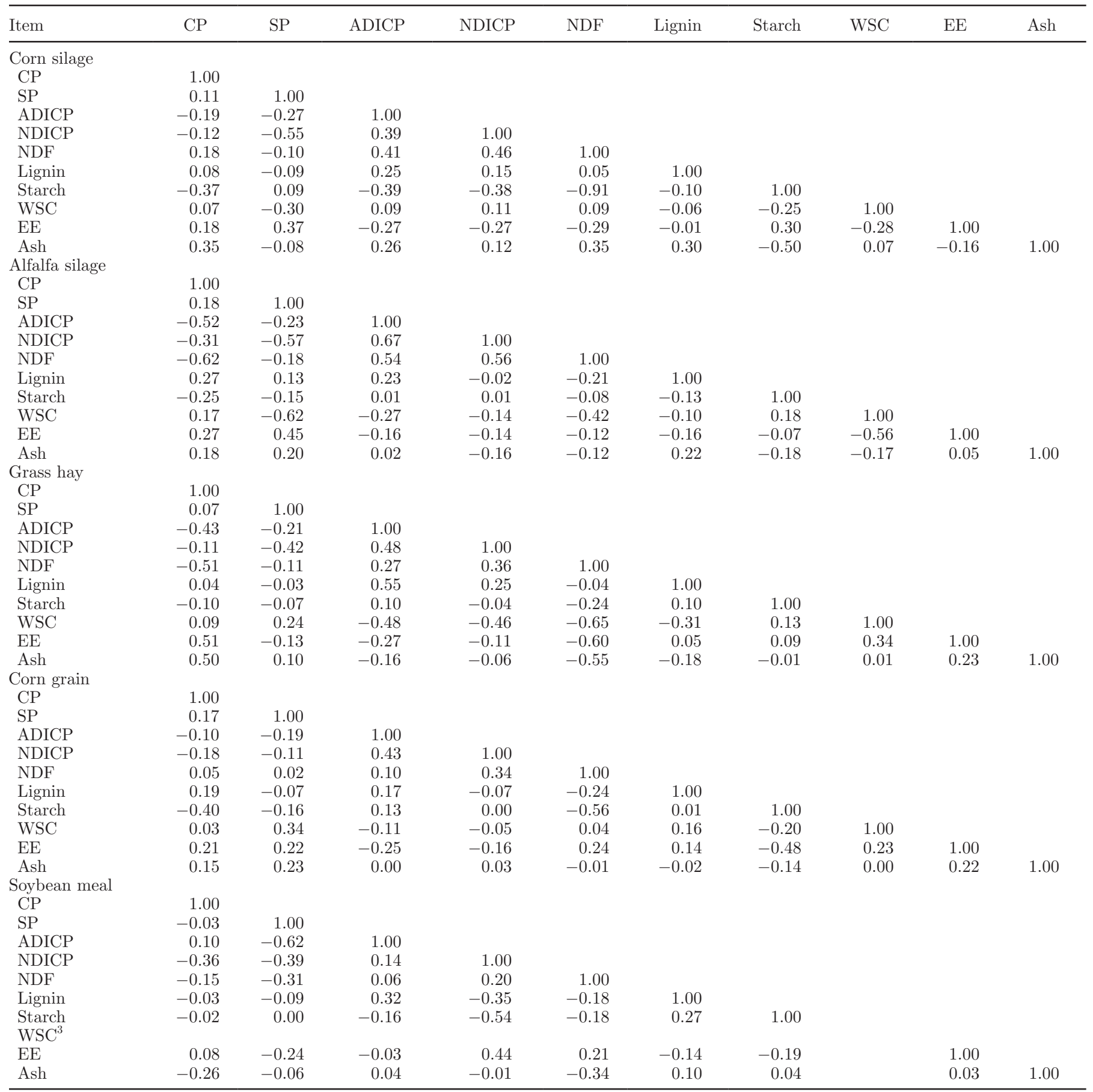

${ }^{1} \mathrm{WSC}=$ water-soluble carbohydrates; $\mathrm{SP}=$ soluble protein; ADICP $=$ acid detergent-insoluble $\mathrm{CP} ; \mathrm{NDICP}=$ neutral detergent-insoluble $\mathrm{CP}$; $\mathrm{EE}=$ ether extract.

${ }^{2}$ Chemical components are expressed as $\%$ of DM except: $\mathrm{SP}=\%$ of $\mathrm{CP} ; \mathrm{ADICP}=\%$ of $\mathrm{CP} ; \mathrm{NDICP}=\%$ of $\mathrm{CP} ; \mathrm{Lignin}=\%$ of $\mathrm{NDF}$.

${ }^{3}$ Row left blank because insufficient data was available to perform the analysis.

to construct a matrix of regression estimates in the arrangement shown below and according to the general form $Y_{i j}=A+B X_{i}$, where $Y$ is the response variable and column vector for the $i$ th component in the $j$ th feed with $n$ entries, $A$ is the intercept arranged in an $n \times$ $p$ matrix, $B$ is the predictor variable arranged in an $n$ $\times p$ matrix, and $X$ is the regression coefficient and row vector for the $i$ th component with $n$ entries: 


$$
Y=\left(\begin{array}{c}
Y_{1} \\
Y_{2} \\
\vdots \\
Y_{n}
\end{array}\right), A=\left(\begin{array}{ccc}
A_{11} & \cdots & A_{1 p} \\
A_{21} & \cdots & A_{2 p} \\
\vdots & \ddots & \vdots \\
A_{n 1} & \cdots & A_{n p}
\end{array}\right), B=\left(\begin{array}{ccc}
B_{11} & \cdots & B_{1 p} \\
B_{21} & \cdots & B_{2 p} \\
\vdots & \ddots & \vdots \\
B_{n 1} & \cdots & B_{n p}
\end{array}\right), X=\left(\begin{array}{c}
X_{1} \\
X_{2} \\
\vdots \\
X_{n}
\end{array}\right),
$$

In this arrangement, if $Y_{n}=X_{n}, A_{n p}=0$ and $B_{n p}=$ 1. For example, if $Y_{1}$ was the response variable $\mathrm{CP}$, then the predictor variable $X_{1}$ would also be CP and the relationship would have an intercept of 0 and slope of 1 . Therefore, equations where $Y_{n}=X_{n}$ were excluded from the matrix. The weighted mean of response variables were calculated across each row of the matrix. The coefficients used to correlate each probability density function for the Monte Carlo simulation (Table 5) were normalized to sum to 1 and then used as weights $(W)$ in the weighted mean (i.e., $\sum_{i=1}^{n} W_{i}=1$, and therefore $\left.\bar{Y}=\sum_{i=1}^{n} W_{i} X_{i}\right)$. Using correlation coefficients as weights meant components within a specific feed that were more highly correlated had more influence on the mean and vice versa.

Components calculated using this method varied depending on the data available for a specific feed. To avoid confounding, components within a feed that were calculated by the matrix were not used as predictor variables for other components in the matrix. Therefore, the number of components calculated using the matrix was limited to avoid running out of predictor variables. Typically, nitrogenous components (SP, ammonia, NDICP, ADICP) not calculated in the preceding steps and not factors in equation [16] were calculated in this step.

\section{Step 4: Optimize to a Final Solution}

Lastly, components that were not assigned values in any of the preceding steps were calculated using an optimization. RISKOptimizer version 5.7 (Palisade Corporation) was used to perform the optimization, which uses a genetic algorithm simulation to find solutions when uncertainty exists around the values (Palisade, 2010b). Minimum and maximum boundaries for each component within a feed were set to constrain the optimizer to a likely range of values. The data used to calculate the range in each component was taken from the databases available online from the commercial laboratories. Each range was calculated as the mean plus or minus the SD of each component multiplied by global coefficient that was adjusted to allow the optimizer to converge. Typically, the coefficient used was between 0.5 and 1.5, meaning the range for each component was the mean plus or minus 0.5 to 1.5 times the SD of each component. An example of the constraints used to optimize corn silage is in Table 6 .

The second constraint applied to the optimization was the relationship described by equation [16]. Components included in the optimization were, therefore, adjusted within the calculated range to the most likely

Table 6. Minimum and maximum boundaries used to constrain the chemical components of corn silage during optimization in step 4 of the procedure used to update the CNCPS feed library

\begin{tabular}{|c|c|c|c|c|}
\hline \multirow[b]{2}{*}{ Chemical component $^{1}$} & \multirow[b]{2}{*}{ Mean } & \multirow[b]{2}{*}{ SD } & \multicolumn{2}{|c|}{ Optimizer boundaries $(1.5 \times \mathrm{SD})$} \\
\hline & & & Minimum & Maximum \\
\hline DM & 33.8 & 10.3 & 18.3 & 49.2 \\
\hline $\mathrm{CP}$ & 8.2 & 1.0 & 6.7 & 9.8 \\
\hline $\mathrm{SP}(\%$ of CP) & 53.4 & 10.1 & 38.3 & 68.5 \\
\hline Ammonia (\% of SP) & 13.4 & 6.2 & 4.1 & 22.7 \\
\hline $\mathrm{ADICP}(\%$ of $\mathrm{CP})$ & 7.5 & 1.8 & 4.8 & 10.2 \\
\hline NDICP ( $\%$ of CP) & 15.2 & 3.8 & 9.6 & 20.9 \\
\hline Acetic & 2.4 & 1.5 & 0.1 & 4.6 \\
\hline Propionic & 0.3 & 0.3 & 0.0 & 0.9 \\
\hline Butyric & 0.0 & 0.0 & 0.0 & 0.2 \\
\hline Lactic & 4.7 & 2.2 & 1.4 & 8.1 \\
\hline Other OA & 0.0 & 0.0 & 0.0 & 0.0 \\
\hline WSC & 2.1 & 1.3 & 0.2 & 4.0 \\
\hline Starch & 31.3 & 7.5 & 20.0 & 42.6 \\
\hline $\mathrm{ADF}$ & 26.1 & 4.1 & 20.0 & 32.2 \\
\hline NDF & 44.1 & 6.0 & 35.1 & 53.1 \\
\hline Lignin ( $\%$ of NDF) & 7.6 & 1.5 & 5.3 & 9.9 \\
\hline Ash & 4.2 & 1.2 & 2.5 & 6.0 \\
\hline $\mathrm{EE}$ & 3.3 & 0.5 & 2.6 & 4.0 \\
\hline
\end{tabular}

${ }^{1}$ Expressed as \% of DM unless otherwise stated. WSC = water-soluble carbohydrates; $\mathrm{SP}=$ soluble protein; $\mathrm{ADICP}=$ acid detergent-insoluble $\mathrm{CP}$; NDICP $=$ neutral detergent-insoluble CP; Other OA = other organic acids; $\mathrm{EE}=$ ether extract. 
values in which equation [16] summed to $100 \%$ DM. The optimization step was completed last in the calculation process to fit the components within each feed together within the described constraints. The process was dynamic in that the values calculated in the optimization fed back into the matrix and regression calculations described above. Typically, the optimizer had to be run numerous times before it would converge and stabilize. If insufficient data were available to perform any of the calculation steps described above, current CNCPS library values were retained. The approach was not acceptable for proprietary feeds due to a lack of robust data of chemical components or the functional nature of some ingredients beyond the nutrient content. For example, products such as Met analogs are partially absorbed through the rumen wall and do not completely flow to the small intestine, yet the supply of Met to the animal or the conservation of the AA due to the supplementation of the analog is documented (Chen et al., 2011). Conventional chemical analysis does not adequately estimate the true nutrient supply for these types of feeds. Current library values were retained in these circumstances. Approximately $75 \%$ of the feeds in the feed library were updated and $25 \%$ remained unchanged. Those remaining unchanged were primarily commercial products, minerals, and vitamins, along with unusual feeds with little information within the databases.

\section{$A A$}

In addition to the chemical components described above, each feed in the CNCPS feed library includes a profile of the 10 essential AA. Amino acid profiles were updated using data sets provided by Evonik Industries AG (Hanau, Germany), Adisseo (Commentry, France), and taken from the NRC (2001). Data provided were mean values from analyses completed in the respective companies' laboratories or published in the NRC (2001). In all cases, AA analyses were completed on the whole feed and are expressed in the CNCPS on a percent CP basis. This differs from previous versions of the CNCPS, where AA were expressed as a percent of the buffer-insoluble residue (O'Connor et al., 1993). The most appropriate profile was assigned based on data availability and was used as received by the source without alteration. If profiles for specific feeds were not available in the data sets provided, current CNCPS values were retained. Proprietary feeds were not changed.

\section{Model Sensitivity}

The sensitivity of model outputs to variation in feed library inputs was also evaluated. The analysis was split into 2 parts. Part 1 looked at the likely range in 6 major chemical components in the diet: (1) CP, (2) starch, (3) NDF, (4) lignin, (5) ash, and (6) EE; and 4 model outputs: (1) ME-allowable milk, (2) MPallowable milk, (3) MP from RUP, and (4) MP from bacteria. To complete this part of the analysis, a reference diet was constructed in a spreadsheet version of the CNCPS (Van Amburgh et al., 2013). The diet was formulated using ingredients typically found in North American dairy cattle rations and was balanced to provide enough ME and MP for a mature, nonpregnant, $600-\mathrm{kg}$ cow in steady state (0 energy balance) to produce $35 \mathrm{~kg}$ of milk containing $3.1 \%$ true protein and $3.5 \%$ fat (Table 7 ). Probability density functions were fit to chemical components within each feed in the reference diet (Table 4) and correlated to each other with Spearman rank order correlations (Table 5) using @Risk version 5.7 (as previously described). Frequency distributions for model outputs were then generated using a Monte Carlo simulation with 10,000 iterations to describe the range of possible outcomes for each output and the relative likelihood of occurrence.

Part 2 of the analysis investigated which feed library inputs for the feeds in the reference diet had the most influence on selected model outputs: (1) ME-allowable milk, (2) MP-allowable milk, (3) MP from RUP, and (4) MP from bacteria. The feed library inputs investigated were those described in part 1 of the analysis, as

Table 7. Diet ingredients, chemical composition, and model predicted ME and MP for the reference diet used to analyze model sensitivity

\begin{tabular}{lr}
\hline Item $^{1}$ & Unit \\
\hline Diet ingredient (kg of DM) & \\
Corn silage & 4.76 \\
Alfalfa silage & 3.14 \\
Grass hay & 4.03 \\
Corn grain ground fine & 6.48 \\
Soybean meal solvent extracted & 2.58 \\
Blood meal & 0.20 \\
Minerals and vitamins & 0.50 \\
Total DMI & 21.69 \\
Diet composition (\% of DM unless stated) & \\
CP & 16.7 \\
SP (\% of CP) & 35.3 \\
ADICP (\% of CP) & 6.4 \\
NDICP (\% of CP) & 15.6 \\
WSC & 3.5 \\
Starch & 29.0 \\
NDF & 31.8 \\
Lignin (\% of NDF) & 11.5 \\
EE & 3.0 \\
Ash & 7.7 \\
Model outputs & \\
ME (Mcal/d) & 53.7 \\
MP (g/d) & 2,385 \\
\hline
\end{tabular}

${ }^{1} \mathrm{WSC}=$ water-soluble carbohydrates; $\mathrm{SP}=$ soluble protein; $\mathrm{ADICP}$ $=$ acid detergent-insoluble CP; NDICP $=$ neutral detergent-insoluble $\mathrm{CP} ; \mathrm{EE}=$ ether extract. 
well as kd for the carbohydrate and protein fractions summarized in Table 2. Probability density functions were fit to each chemical component within each feed as previously described. Program Evaluation and Review Technique (PERT) distributions (Cottrell, 1999) were used to describe the variation in $\mathrm{kd}$. The PERT distribution is similar to a $\beta$ or triangular distribution and is useful to describe variation in a situation where limited data exists (Johnson, 1997). The PERT distribution requires 3 estimates: (1) the most likely result; (2) the minimum expected result; and (3) the maximum expected result. Most likely results were set as CNCPS feed library values. Minimum and maximum values were set as the most likely value $\pm 2 \mathrm{SD}$ to encompass approximately $95 \%$ of the expected data without including extreme results (Table 8). Data on $\mathrm{kd}$ are scarce and, other than the CB3 fraction, are not routinely estimated for model input. Variation in $\mathrm{kd}$ changes proportionally to changes in mean values (Weiss, 1994). Therefore, in situations where data were not available, the proportional variation relative to the mean of other known feeds was used as a proxy to calculate the minimum and maximum values of unknown feeds. The CB3 $\mathrm{kd}$ was calculated for the forage feeds in the reference diet using lignin $\times 2.4$ and 30 -h in vitro NDF digestibility as described by Van Amburgh et al. (2003). Variation in $\mathrm{kd}$ for fractions other than CB3 were estimated from literature values. Fractions CA1-4 and CB1-2 kd were estimated from the soluble and potentially degradable fractions presented in Offner et al. (2003). The PB2 fractions (fiber-bound protein) were set to equal the CB3 fractions as described by Van Amburgh et al. (2007), The PB1 values were taken from the NRC (2001) and PA2 values were estimated from Broderick (1987). Correlation coefficients among components were not assigned for this part of the analysis as the interest was in understanding model sensitivity to individual components independent of correlated changes in composition. To complete the analysis, a Monte Carlo simulation with 10,000 iterations was performed. Changes in model outputs resulting from a 1 SD increase in model inputs were captured and are presented in Figures 2, 3, and 4.

\section{RESULTS AND DISCUSSION}

\section{Analytical Techniques and Fractionation}

The required procedures to most appropriately characterize the chemical components of feeds for version 6.5 of the CNCPS are described in Table 1. Chemical components and fractionation of feeds in the updated library were maintained in the format described by Tylutki et al. (2008) with the exception of the pro- tein A1 fraction. Previously this has been classified as NPN, which is measured as the nitrogen passing into the filtrate after extraction of the soluble component with borate-phosphate buffer and precipitation of the true protein fraction from the supernatant with $10 \%$ trichloroacetic acid (Krishnamoorthy et al., 1982). The protein A1 fraction is typically assumed completely degraded in the rumen (Lanzas et al., 2007b). However, small peptides and free AA not precipitated by this method are still nutritionally relevant to the animal if they escape rumen degradation and flow through to the small intestine (Givens and Rulquin, 2004). Choi et al. (2002) suggested $10 \%$ of the AA flowing through to the small intestine originated from dietary NPN sources that, under the previous approach within the CNCPS, were unaccounted for. Reynal et al. (2007) conducted a similar study and measured soluble AA flows at the omasum ranging from 9.2 to $15.9 \%$ of total AA flow. Likewise, Velle et al. (1997) infused free AA into the rumen at various rates and showed that up to $20 \%$ could escape degradation and flow through to the small intestine, which is in agreement with data from Volden et al. (1998). Van Amburgh et al. (2010) suggested it might be more appropriate to redefine the protein A1 fraction from NPN as described by Krishnamoorthy et al. (1982) to ammonia. This would shift small peptides and free AA currently associated with the A1 fraction into the A2 fraction, where they could contribute to MP supply, and also refines the prediction of rumen $\mathrm{N}$ balance as less $\mathrm{N}$ is degraded in the rumen. Ammonia has the advantage of being easily measured and available from most commercial laboratories. Therefore, the NPN fraction in previous feed libraries has been updated to ammonia in version 6.5 (Van Amburgh et al., 2013).

Amino acid profiles from the original feed database (O'Connor et al., 1993) were determined on the insoluble protein residue and analyzed using a single acid hydrolysis with $6 \mathrm{~N} \mathrm{HCl}$ for $24 \mathrm{~h}$ (Macgregor et al., 1978; Muscato et al., 1983). During acid hydrolysis, Met is partially converted to methionine sulfoxide, which cannot be quantitatively recovered, and Trp is completely destroyed (Allred and MacDonald, 1988). Methionine is typically considered one of the most limiting AA in dairy cattle diets (Schwab et al., 1992; Armentano et al., 1997; Rulquin and Delaby, 1997) and is frequently the target of supplementation (Schwab, 1996). Therefore, updating AA profiles in the feed library, particularly Met, was an important part of improving overall model predictions. The AA profiles used to update the feed library were analyzed on a whole-feed basis, rather than on the insoluble protein residue. The insoluble protein residue was originally assumed to have a greater probability of escaping the rumen and was more likely to 
Table 8. Parameters used to specify program evaluation and review technique (PERT) distributions (mean, minimum, and maximum) and SD for the digestion rates of carbohydrate and protein fractions of feeds in the reference diet used to analyze model sensitivity

\begin{tabular}{|c|c|c|c|c|c|c|c|c|c|c|c|c|c|}
\hline \multirow[b]{2}{*}{ Item } & \multicolumn{13}{|c|}{ Carbohydrate and protein fractions ${ }^{1}$} \\
\hline & CA1 & $\mathrm{CA} 2$ & $\mathrm{CA} 3$ & $\mathrm{CA} 4$ & CB1 & $\mathrm{CB} 2$ & CB3 & $\mathrm{CC}$ & PA1 & $\mathrm{PA} 2$ & PB1 & PB2 & $\mathrm{PC}$ \\
\hline \multicolumn{14}{|l|}{ Corn silage } \\
\hline Mean & 0.0 & 7.8 & 5.6 & 22.3 & 35.7 & 33.5 & 3.8 & 0.0 & 200.0 & 50.0 & 20.0 & 3.8 & 0.0 \\
\hline $\mathrm{SD}$ & 0.0 & 3.5 & 2.5 & 10.0 & 16.1 & 15.1 & 0.7 & 0.0 & 15.1 & 6.6 & 5.2 & 0.7 & 0.0 \\
\hline Minimum & 0.0 & 0.2 & 0.1 & 0.2 & 0.6 & 0.7 & 1.9 & 0.0 & 161.1 & 32.8 & 6.8 & 1.9 & 0.0 \\
\hline Maximum & 0.0 & 18.2 & 13.0 & 52.4 & 82.8 & 78.6 & 5.6 & 0.0 & 238.4 & 66.8 & 33.4 & 5.7 & 0.0 \\
\hline SD & 0.0 & 1.4 & 1.0 & 4.0 & 6.0 & 7.0 & 1.4 & 0.0 & 15.1 & 6.0 & 5.0 & 1.4 & 0.0 \\
\hline Minimum & 0.0 & 3.4 & 2.5 & 9.9 & 14.6 & 17.1 & 3.5 & 0.0 & 161.3 & 29.7 & 3.3 & 3.4 & 0.0 \\
\hline Maximum & 0.0 & 10.5 & 7.6 & 30.1 & 45.2 & 52.8 & 10.5 & 0.0 & 238.9 & 60.2 & 28.6 & 10.5 & 0.0 \\
\hline \multicolumn{14}{|l|}{ Grass hay } \\
\hline Mean & 0.0 & 7.0 & 5.0 & 40.0 & 30.0 & 30.0 & 4.5 & 0.0 & 200.0 & 20.0 & 14.0 & 4.5 & 0.0 \\
\hline SD & 0.0 & 1.4 & 1.0 & 8.0 & 6.0 & 6.0 & 1.0 & 0.0 & 15.1 & 2.7 & 5.1 & 1.0 & 0.0 \\
\hline Minimum & 0.0 & 3.5 & 2.4 & 19.8 & 14.6 & 14.8 & 1.9 & 0.0 & 161.4 & 13.2 & 0.7 & 1.9 & 0.0 \\
\hline Maximum & 0.0 & 13.2 & 9.5 & 76.7 & 28.6 & 38.0 & 9.2 & 0.0 & 238.8 & 21.4 & 16.1 & 9.1 & 0.0 \\
\hline \multicolumn{14}{|c|}{ Soybean meal } \\
\hline Mean & 0.0 & 7.0 & 5.0 & 40.0 & 25.0 & 30.0 & 6.0 & 0.0 & 200.0 & 24.0 & 11.0 & 6.0 & 0.0 \\
\hline SD & 0.0 & 2.2 & 1.6 & 12.5 & 7.8 & 9.4 & 1.2 & 0.0 & 15.1 & 3.2 & 2.7 & 1.2 & 0.0 \\
\hline Minimum & 0.0 & 1.4 & 1.0 & 7.9 & 5.2 & 5.8 & 2.9 & 0.0 & 161.3 & 15.9 & 4.2 & 2.8 & 0.0 \\
\hline Maximum & 0.0 & 12.5 & 9.0 & 71.9 & 45.3 & 53.9 & 9.1 & 0.0 & 238.8 & 32.1 & 17.8 & 9.2 & 0.0 \\
\hline \multicolumn{14}{|l|}{ Blood meal } \\
\hline Mean & 0.0 & 0.0 & 0.0 & 0.0 & 0.0 & 0.0 & 0.0 & 0.0 & 200.0 & 13.5 & 3.7 & 0.0 & 0.0 \\
\hline SD & 0.0 & 0.0 & 0.0 & 0.0 & 0.0 & 0.0 & 0.0 & 0.0 & 15.1 & 1.8 & 1.9 & 0.0 & 0.0 \\
\hline Minimum & 0.0 & 0.0 & 0.0 & 0.0 & 0.0 & 0.0 & 0.0 & 0.0 & 161.4 & 8.9 & 0.0 & 0.0 & 0.0 \\
\hline Maximum & 0.0 & 0.0 & 0.0 & 0.0 & 0.0 & 0.0 & 0.0 & 0.0 & 238.4 & 18.1 & 9.7 & 0.0 & 0.0 \\
\hline
\end{tabular}

${ }^{1} \mathrm{CA} 1=$ acetic + propionic + butyric + isobutyric; $\mathrm{CA} 2=$ lactic CA3 $=$ other organic acids; $\mathrm{CA} 4=\mathrm{WSC} ; \mathrm{CB} 1=$ starch; $\mathrm{CB} 2=$ soluble fiber; $\mathrm{CB} 3=$ digestible fiber; $\mathrm{CC}=$ indigestible fiber; $\mathrm{PA} 1=$ ammonia; $\mathrm{PA} 2=$ soluble true protein; $\mathrm{PB} 1=$ insoluble true protein; $\mathrm{PB} 2=$ fiber-bound protein; $\mathrm{PC}=$ indigestible protein.

match the AA profile of the RUP fraction (Macgregor et al., 1978). However, Tedeschi et al. (2001) investigated this hypothesis and found no differences in AA profiles of feeds analyzed with or without extraction of the soluble fraction. Furthermore, the soluble fraction of feeds has been shown to contribute 10 to $20 \%$ to the flow of AA to the small intestine (Velle et al., 1997; Volden et al., 1998; Choi et al., 2002). Extracting the insoluble protein residue requires soaking samples in borate-phosphate buffer to remove the soluble fraction (Krishnamoorthy et al., 1982) and adds another step to AA analysis. Therefore, it was decided using AA profiles determined on a whole-feed basis was simpler, more feasible for commercial laboratories, biologically more relevant, and provided access to much larger data sets than using profiles from the insoluble residue.

\section{Revision of the Feed Library}

The process of evaluating and updating the feed library was designed specifically to pool data from vari- ous sources and combine it to estimate likely values. Although the data set used in our analysis encompassed a large number of samples from a wide range of situations, information on environmental and management factors implicit in the composition of individual samples were not available. Many external factors affect the nutrient composition of feeds both pre- and postharvest. When considering forages, preharvest environmental factors such as temperature, light intensity, nitrogen availability, water, and predation affect quality and composition (Van Soest et al., 1978). Postharvest, management factors such as packing density, particle size, silo type, silo filling rate, and the way in which the face of the silo is managed can affect ADF, NFC, ADICP, SP, ammonia, $\mathrm{pH}$, surface temperature, and aerobic instability (Ruppel et al., 1995). Furthermore, biological processes during ensiling such as plant respiration, plant enzymatic activity, clostridial activity, and aerobic microbial activity will affect levels of rapidly fermentable $\mathrm{CHO}$, AA, and NPN and can lead to heating and Maillard reactions (Muck, 1988). Analytically, elevated levels 

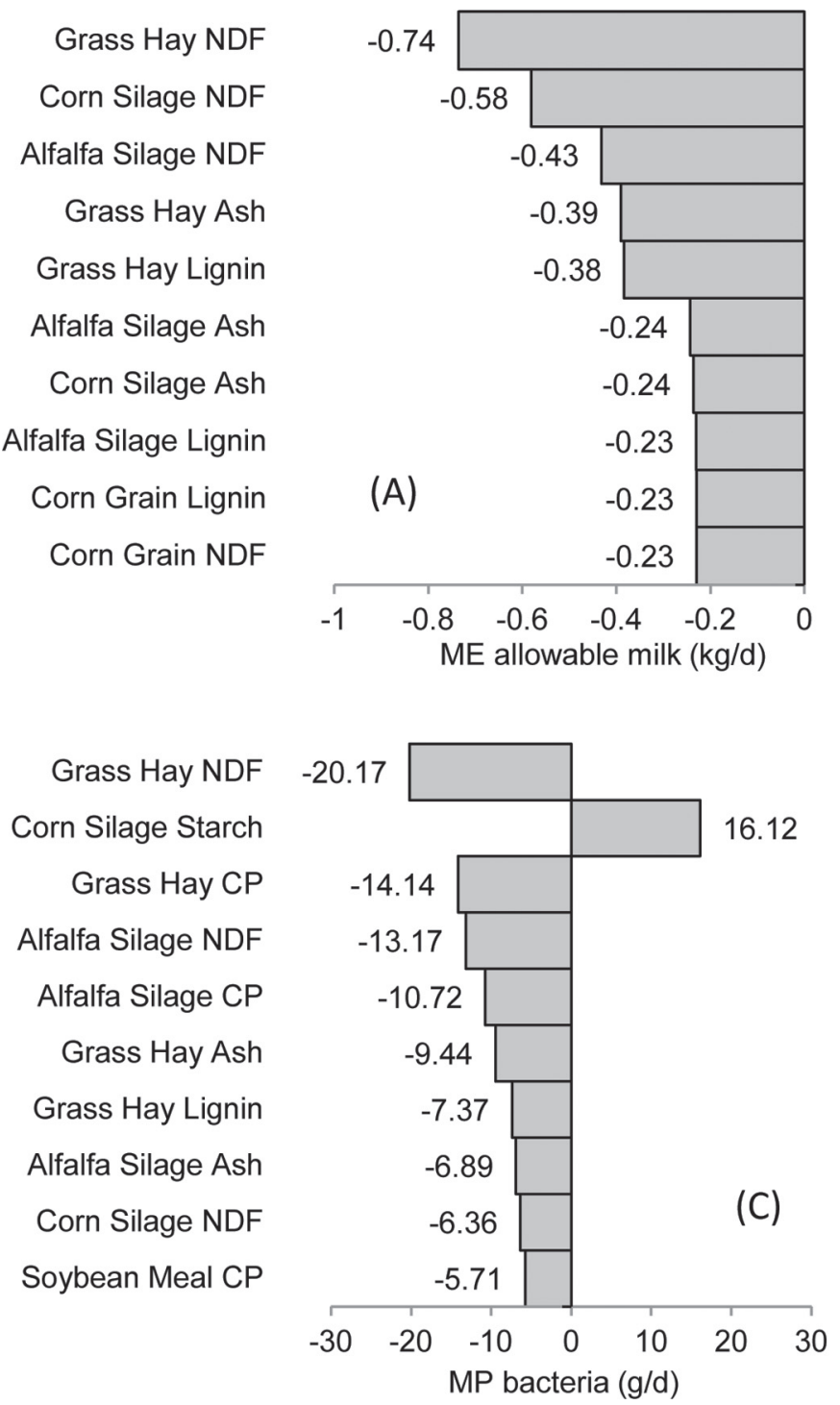
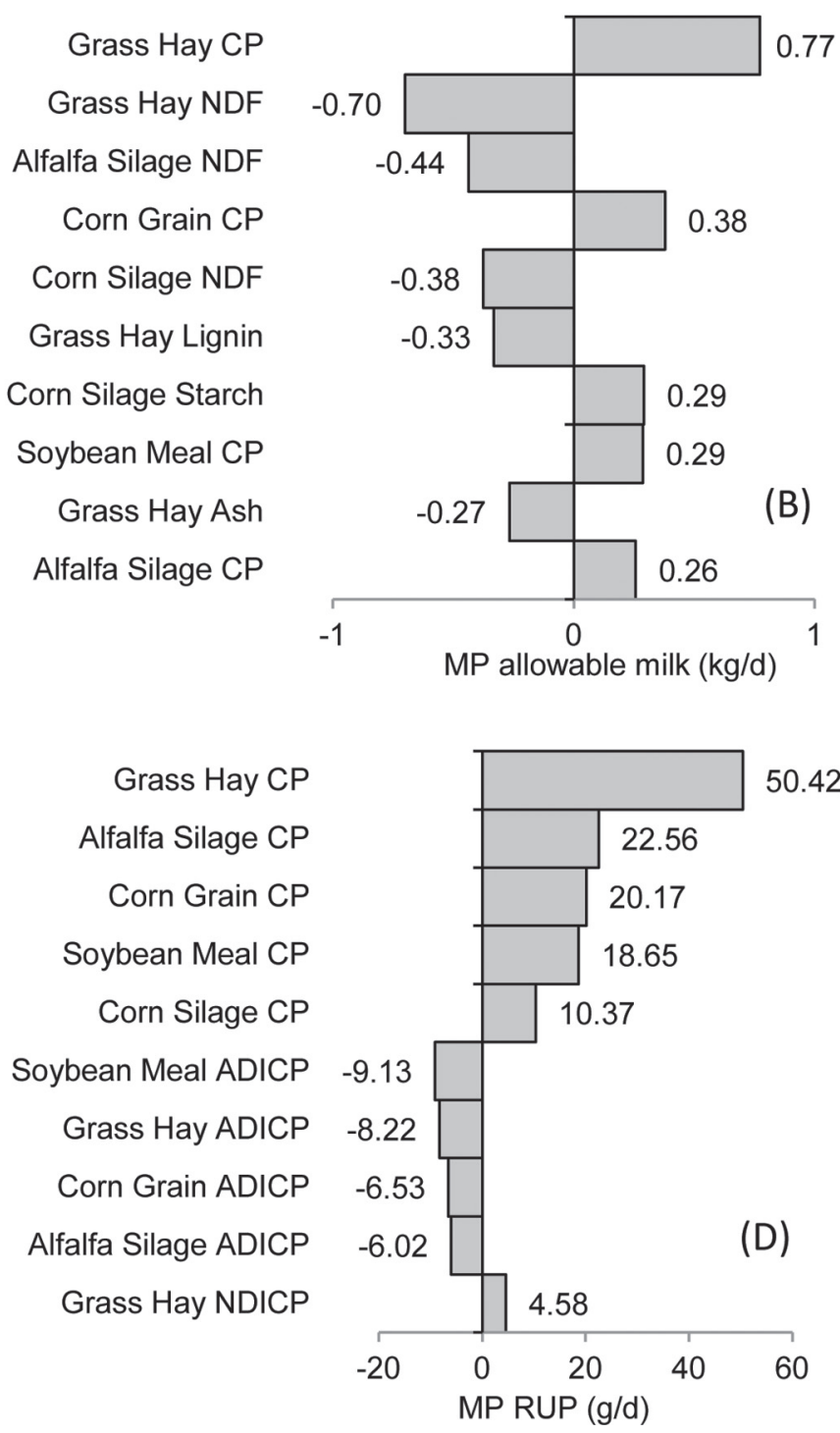

Figure 2. Change in model output from a $1 \mathrm{SD}$ increase in the chemical components of feeds used in the reference diet ranked in order of importance. $\mathrm{ADICP}=$ acid detergent-insoluble $\mathrm{CP}$; NDICP $=$ neutral detergent-insoluble $\mathrm{CP}$.

of ADICP are indicative that Maillard reactions have occurred and are common in many heat-dried feeds and fermented feeds where excessive heating occurred (Van Soest and Mason, 1991). Given the importance of external factors on the composition of different feeds, the process used in our project was not sensitive enough to accurately predict the composition of feeds on a sample-by-sample basis. However, it was capable of producing estimated compositions under average conditions in an efficient and repeatable manner that was useful for reviewing and updating a large database such as the CNCPS feed library.

Examples of the changes made to selected forages and concentrates are in Figures 5 and 6. The figures were constructed so that the 0 point on the y-axis represents the mean of the data set used to update the composition (given in brackets on the x-axis) and the error bars represent \pm 1 SD from the mean. The new and old values for each chemical component within the example feeds are presented relative to the mean and SD. For forage feeds, typically multiple options were available for each feed in the feed library. Therefore, some deviation from the mean could be expected, as the variation is what makes the individual option unique (e.g., high NDF, low NDF). In contrast, the concentrate feeds typically had only one option. In this case, the composition could be expected to be similar to the mean (Figure 6). Noteworthy changes that 


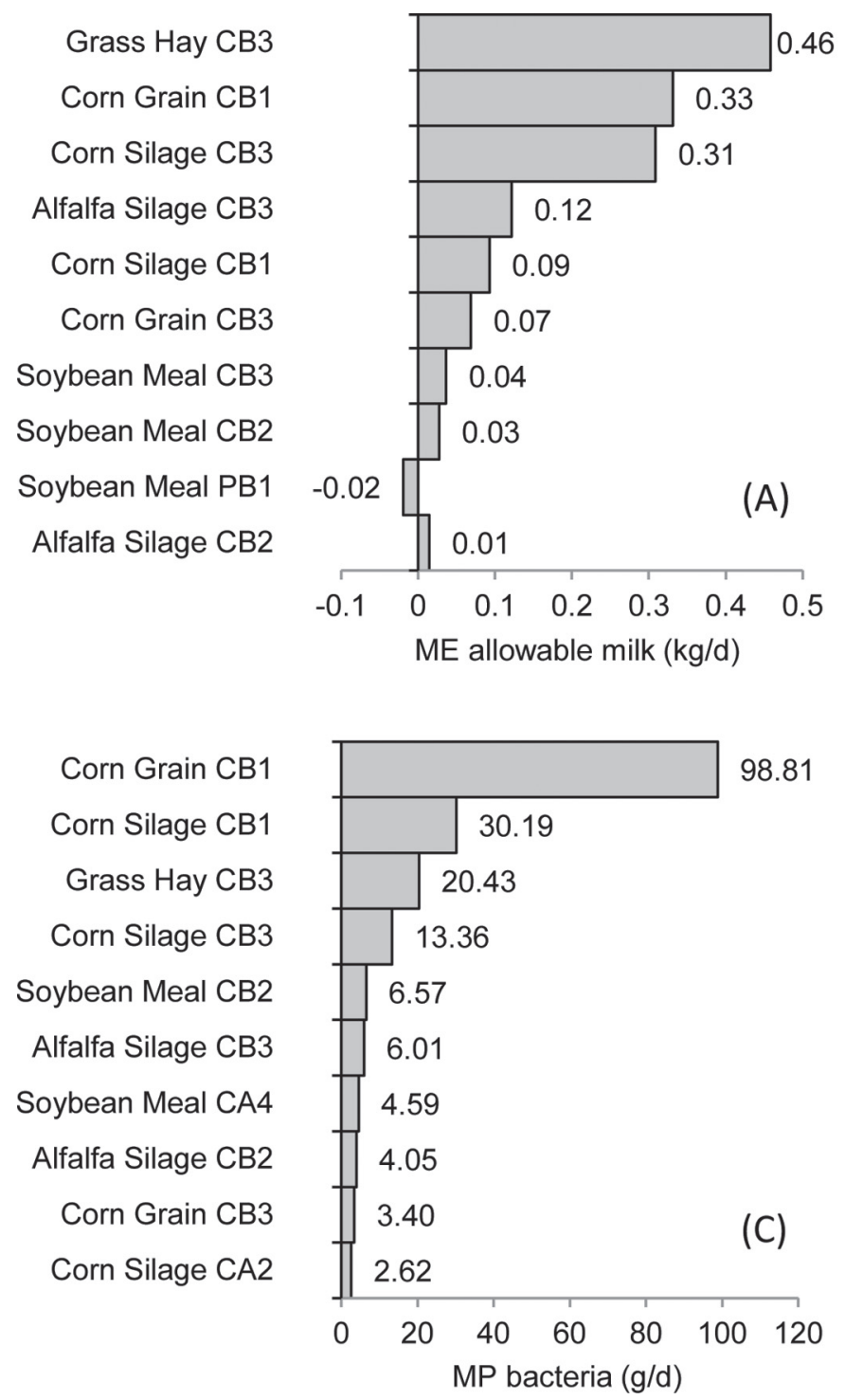

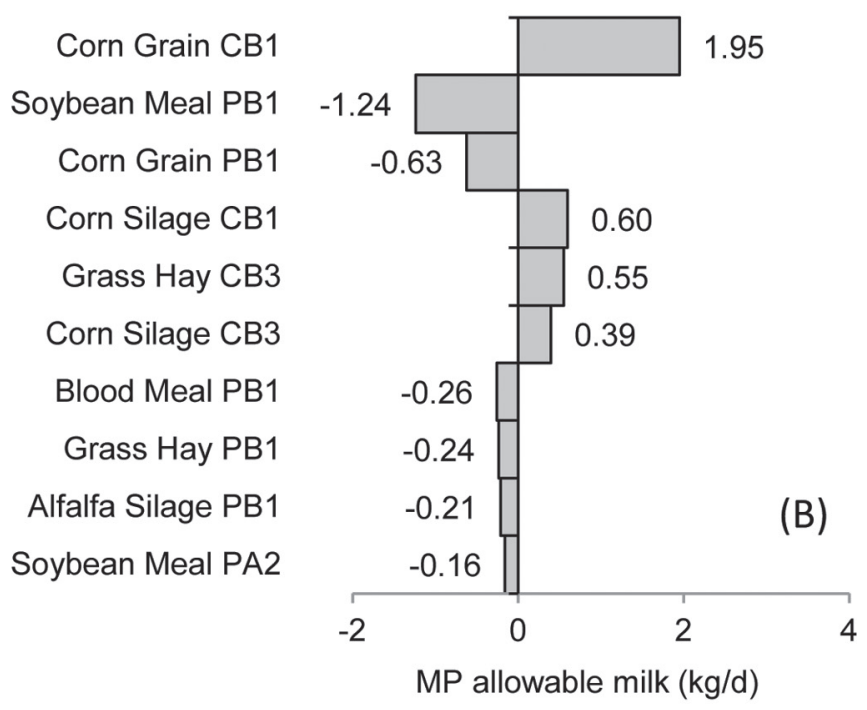

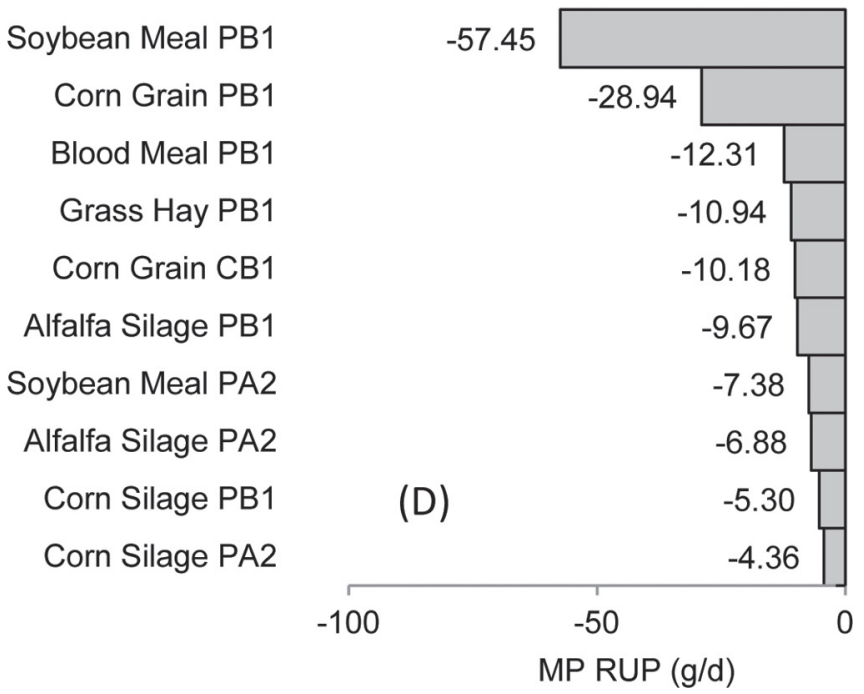

Figure 3. Change in model output from a 1-SD increase in the digestion rates of carbohydrate and protein fractions of feeds used in the reference diet ranked in order of importance. CA2 = lactic acid; CA4 = water-soluble carbohydrates $($ WSC); CB1 = starch; CB2 = soluble fiber; $\mathrm{CB} 3=$ digestible fiber; $\mathrm{PA} 2=$ soluble true protein; $\mathrm{PB} 1=$ insoluble true protein.

reflect some of the relationships observed in the data set include a reduction in starch for the corn silage in Figure 5A. Starch and NDF in corn silage have a strong reciprocal relationship $(\mathrm{r}=-0.91$; Table 5) and $\mathrm{NDF}$ in the example is approximately 6 units greater than the mean. Based on the correlation, starch in this example should be a similar magnitude below the mean, which is reflected by the updated composition. In another example, the composition of canola meal in the old feed library (Figure 6B) was similar to mean values for all components other than starch, which was considerably higher, and outside the expected range. In this case the recalculation procedure reduced starch to within $1 \mathrm{SD}$ of the mean. Similar adjustments were made on a feed-by-feed basis for the entire feed library.

\section{Model Sensitivity to Variation in Feed Chemistry and Digestion Kinetics}

Analyzing model sensitivity to variation in inputs can help users understand where emphasis should be placed when requesting feed analyses and also help identify target areas for investigation if model outputs deviate from expected or observed outcomes. The variation in our study represents an entire population of samples for each feed analyzed over numerous growing seasons. 

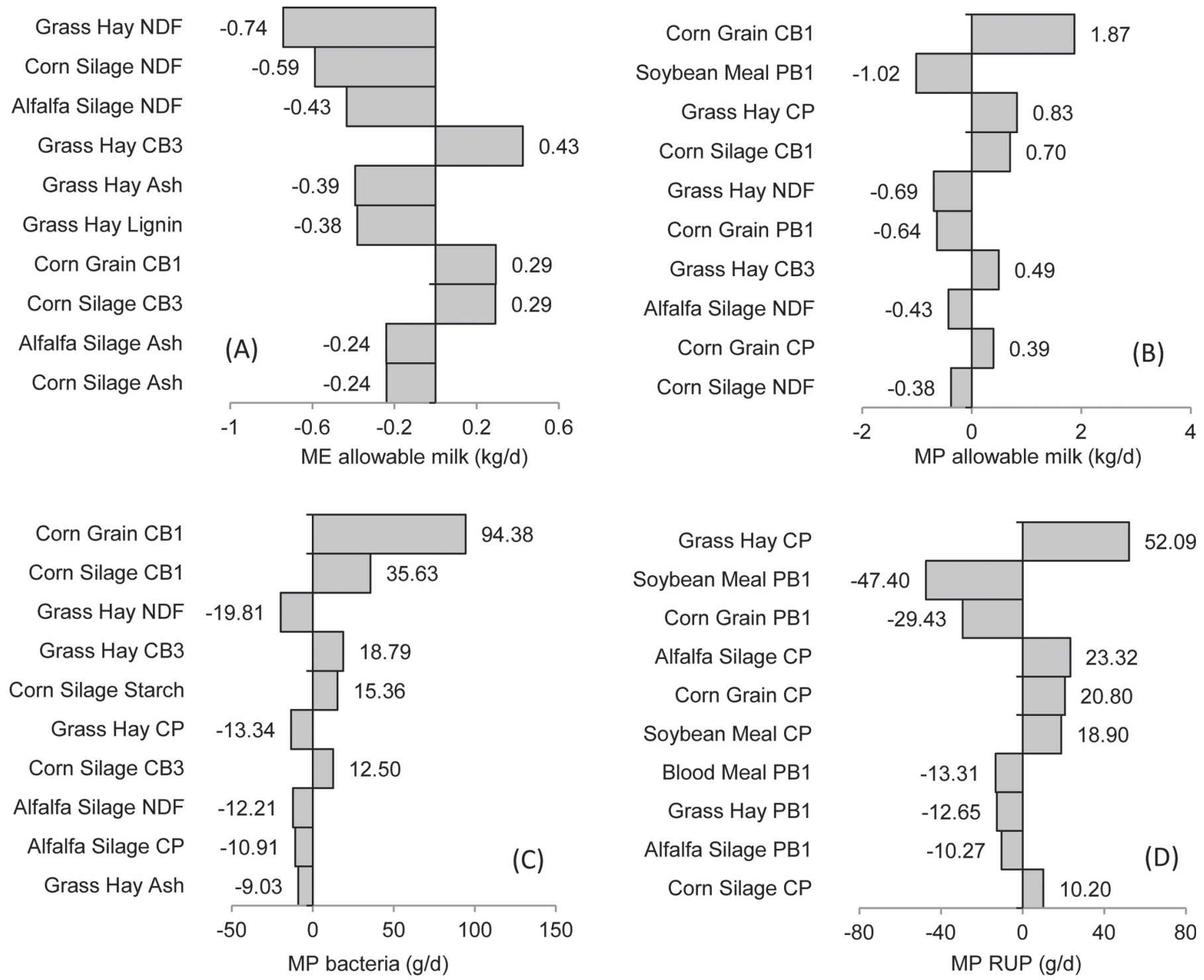

Figure 4. Change in model output from a 1-SD increase in both the chemical components and digestion rates of carbohydrate and protein fractions of feeds used in the reference diet. Items are ranked in order of importance. $\mathrm{CB} 1=$ starch; CB2 $=$ soluble fiber; CB3 = digestible fiber; $\mathrm{PB} 1=$ insoluble true protein.

Therefore, the variation encompassed is what might be expected if a user ran a simulation in the CNCPS using feeds from the feed library with no information on actual feed chemistry. The mean, SD, and distribution for the components considered in our analysis are in Table 4 and are similar to other reports where the same components and feeds are presented (Kertz, 1998; Lanzas et al., 2007a,b). Data rarely fit a normal distribution and were more commonly represented by a loglogistic distribution, similar to the findings of Lanzas et al. (2007a,b). The data of some components were skewed and were better represented by distributions, such as the Beta, Pearson, or Weibull (Table 4). When data are skewed, the mean and SD are less appropriate in describing centrality and dispersion of a population (Law and Kelton, 2000). Outputs of deterministic models, such as the CNCPS, represent an average (Lanzas et al., 2007b); however, when input variation is accounted for, the mean value may no longer represent the most likely value. For example, in Figure 7A, the mean value for ME allowable milk is $34.1 \mathrm{~kg} / \mathrm{d}$; however, the most likely value based on frequency of occurrence is 36.3 $\mathrm{kg} / \mathrm{d}$. These types of considerations are particularly important when conducting model evaluations, as studies rarely report adequate information to complete a robust model simulation (Higgs et al., 2012, Pacheco 
HIGGS ET AL.
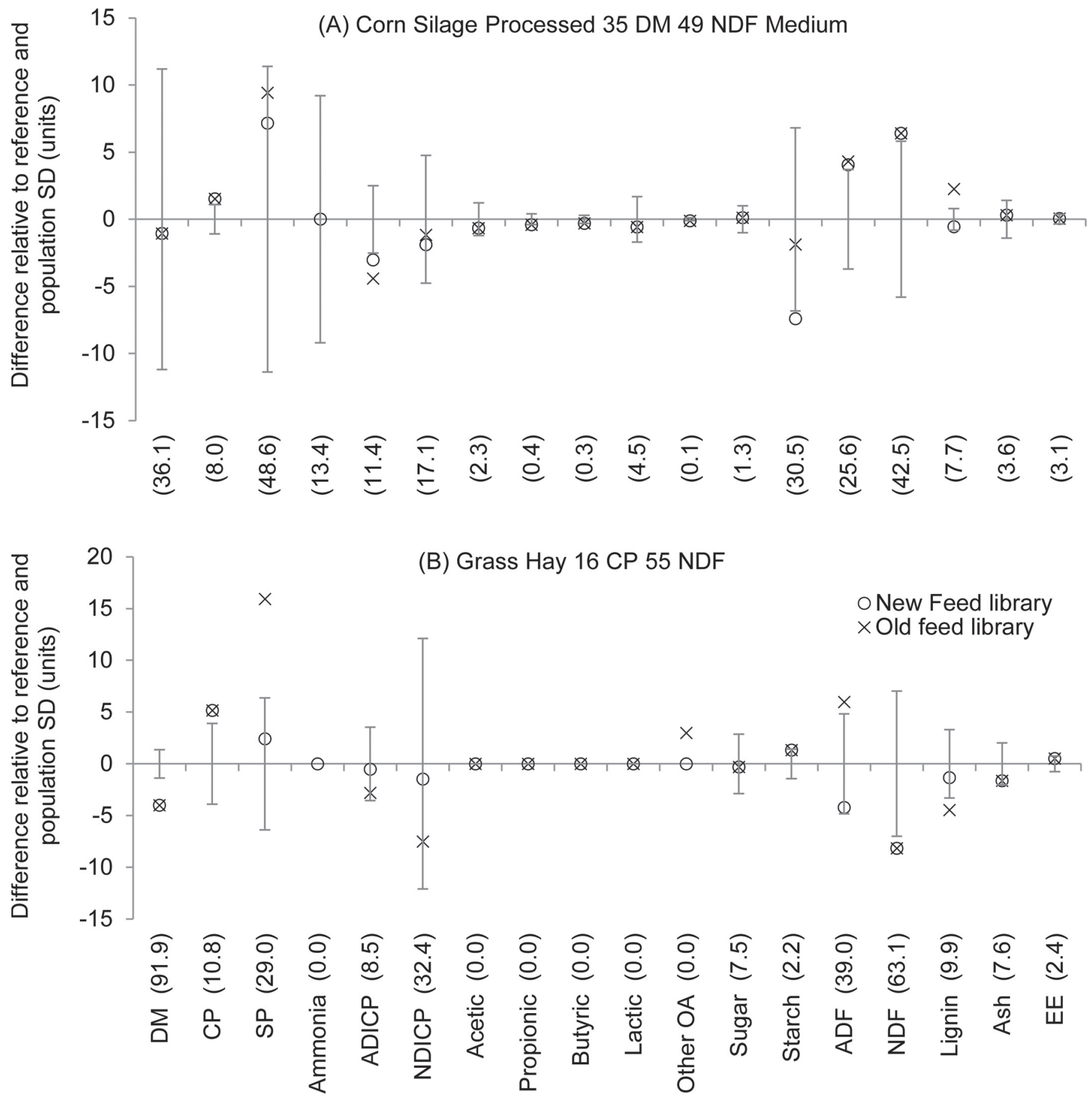

\section{Chemical component (mean of data set; \%)}

Figure 5. Comparison of the relative difference in chemical composition between the old $(\times)$ and new $(\bigcirc)$ Cornell Net Carbohydrate and Protein System feed library for 2 forages (A = corn silage processed 35\% DM, 49\% NDF medium processed; B = grass hay 16\% CP, $55 \%$ NDF) using the mean and SD of commercial laboratory data sets as a reference (Cumberland Valley Analytical Services Inc., Maugansville, MD, and Dairy One Cooperative Inc., Ithaca, NY). All components are expressed as percent DM with the exception of soluble protein (SP; percent CP), ammonia (percent SP), acid detergent-insoluble CP (ADICP; percent $\mathrm{CP}$ ), neutral detergent-insoluble CP (NDICP; percent CP), and lignin (percent $\mathrm{NDF}) . \mathrm{OA}=$ organic acids; $\mathrm{EE}=$ ether extract. 
UPDATING AND ASSESSING THE CNCPS FEED LIBRARY

吕
(A) Corn Grain Ground Fine
8.0

7

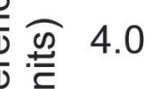

4.0

$-T$

足

0.0

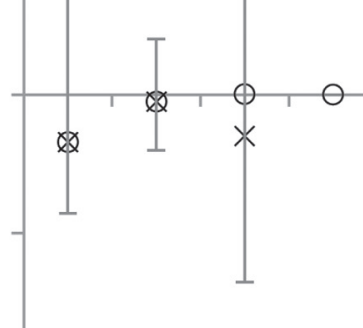

$-4.0$

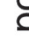

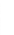

$-8.0$

$-12.0$

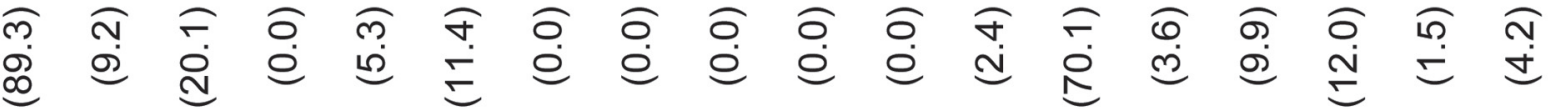

它

(B) Canola Meal Solvent

O New Feed library

$\times \quad \times$ Old feed library

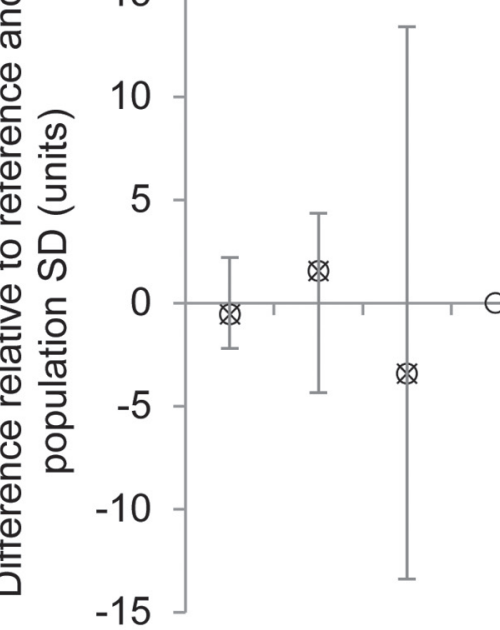

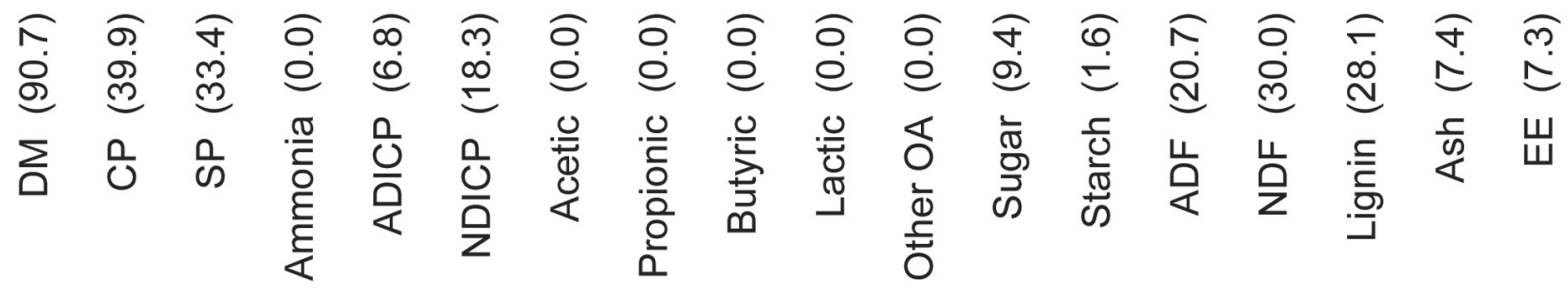

\section{Chemical component (mean of data set; \%)}

Figure 6. Comparison of the relative difference chemical composition between the old $(\times)$ and new $(\bigcirc)$ feed library of 2 concentrate feeds $(A$ = corn grain ground fine; $\mathrm{B}=$ canola meal solvent) using the mean and SD of the online laboratory data sets as a reference (Cumberland Valley Analytical Services Inc., Maugansville, MD, and Dairy One Cooperative Inc., Ithaca, NY). All components are expressed as percent DM with the exception of soluble protein (SP; percent $\mathrm{CP}$ ), ammonia (percent $\mathrm{SP}$ ), acid detergent-insoluble $\mathrm{CP}$ (ADICP; percent CP), neutral detergentinsoluble $\mathrm{CP}$ (NDICP; percent $\mathrm{CP}$ ), and lignin (percent NDF). $\mathrm{OA}=$ organic acids; $\mathrm{EE}=$ ether extract. 

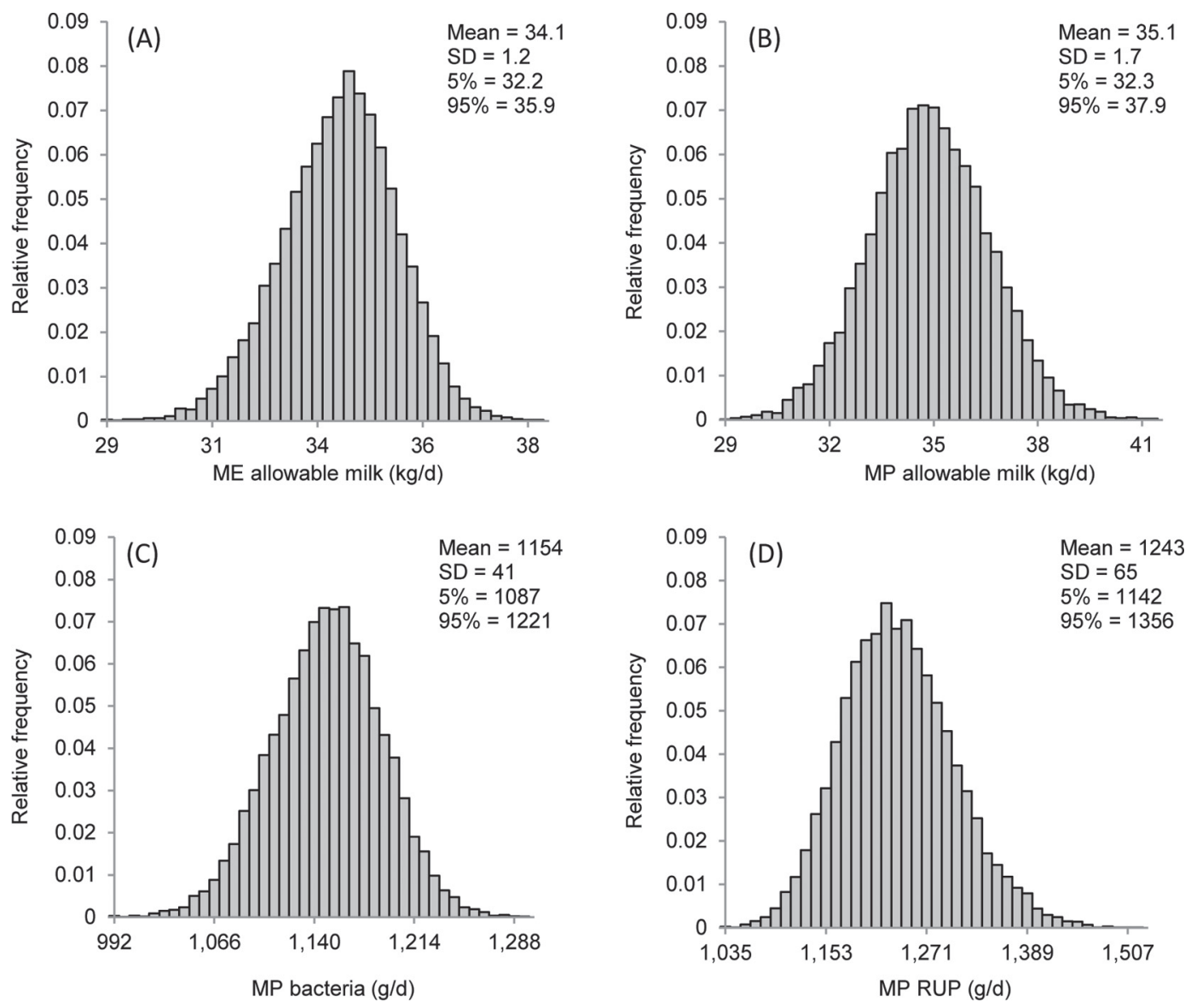

Figure 7. Frequency distributions generated from a Monte Carlo simulation for selected model outputs from the reference diet. Each graph displays the range of possible outcomes for each component and the relative likelihood of occurrence.

et al., 2012). Feed library defaults are typically used in place of reported data leading to the type of variation and bias reported in Figures 7 and 8. Presenting model outputs in the CNCPS as frequency distributions, similar to Figures 7 and 8, could be useful for aid users in managing risk, particularly when balancing rations close to animal requirements. Estimating the variation associated with the sampling process, sample handling, preparation, and the variation of the assay itself within and among labs could be challenging (Hall and Mertens, 2012).

The relative importance of specific model inputs was also investigated. This part of the analysis included variation from both feed composition and the kd values for the $\mathrm{CHO}$ and protein fractions. For this analysis, correlations were not fit to chemical components meaning, during the simulation, values were drawn from probability density functions independently of each other. The rationale for treating components as independent was to understand model behavior irrespective of biological relationships in feed composition. In doing this, insight can be gained into the laboratory analyses that are most critical to predict target model outputs.

The chemical components the model was most sensitive to differed among the outputs considered (Figure 2 ). Prediction of ME allowable milk was most sensitive to forage NDF, lignin and ash whereas MP allowable milk was most sensitive to $\mathrm{CP}$ along with $\mathrm{CHO}$ components and ash. Interestingly, ME-allowable milk was negatively correlated with all the items it was most sensitive to, with a 1-SD increase in grass hay NDF resulting in a $0.74 \mathrm{~kg} / \mathrm{d}$ reduction in ME-allowable milk (Figure 2A). This behavior can be attributed to aspects of the models internal structure; ME in the CNCPS is calculated using the apparent TDN system described by Fox et al. (2004) where the net energy derived from the diet is empirically calculated from an estimate of total-tract nutrient digestion. In this system, carbohydrate intake is calculated by difference according to equation 1 in Table 2, and total-tract nutrient digestion is calculated as the difference between nutrient intake and fecal output. Error in laboratory analysis that 

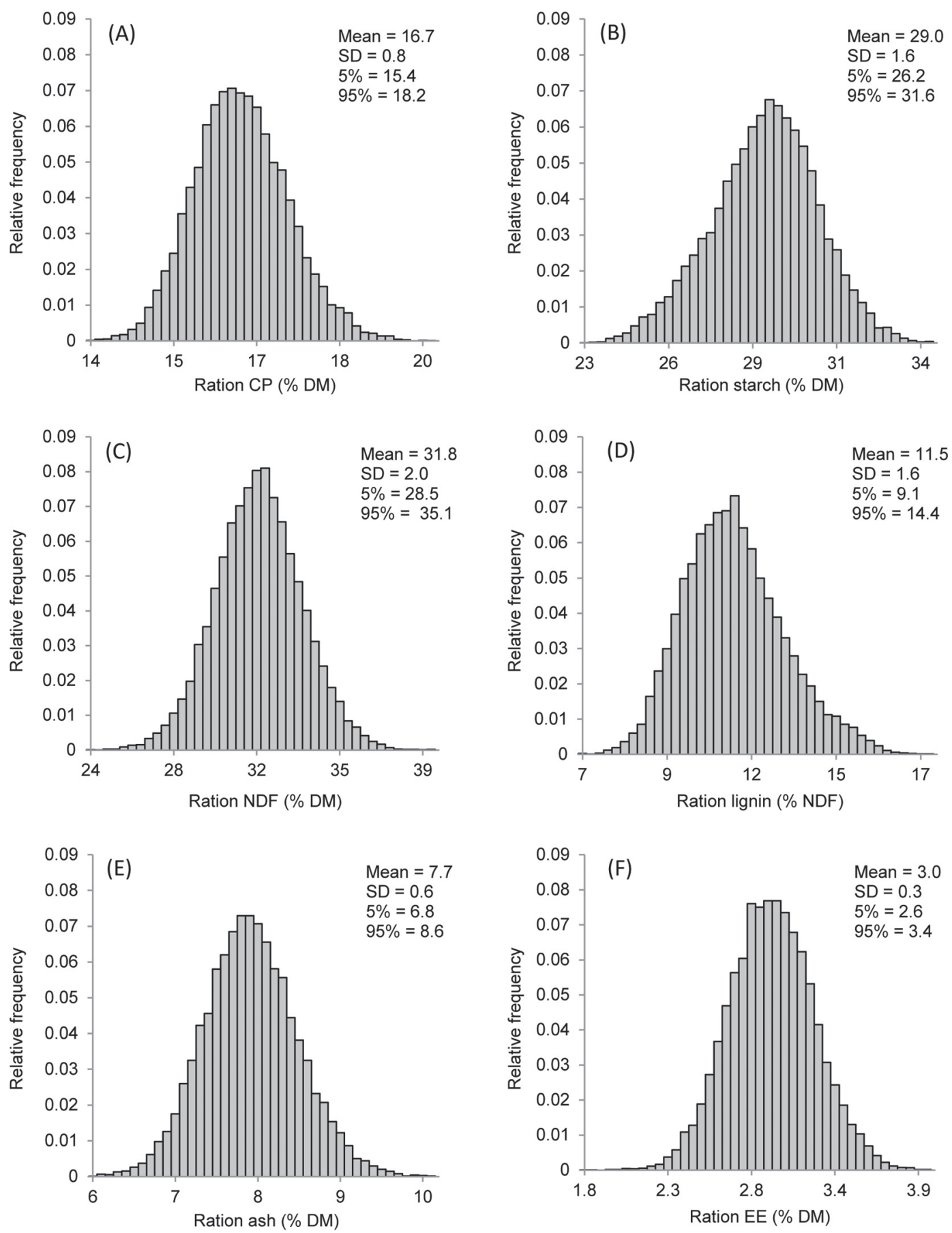

Figure 8. Frequency distributions generated from a Monte Carlo simulation for selected chemical components in the reference diet. Each graph displays the range of possible outcomes for each component and the relative likelihood of occurrence. EE $=$ ether extract.

forces equation [16] to a sum $>100 \%$ DM leads to an overestimation of fecal appearance and an underestimation of apparent TDN. Further, because soluble fiber is also calculated by difference (equation [5]; Table 2), an increase in the concentration of any component less digestible than soluble fiber (i.e., NDF) results in an increase in fecal nutrient appearance and decrease in apparent TDN. For these reasons, ensuring laboratory results are internally consistent and adhering to the framework of equation [16] is critical for the accurate prediction of ME. Furthermore, due to the potential to obscure the true NDF content of forages, the adoption 
of the aNDFom procedure is strongly suggested for current formulation and diet evaluations, as suggested by Sniffen et al. (1992). Although not a part of the library edits, evaluations of ME and MP predictions were improved when aNDFom was used, especially in cases where ash contamination of the NDF was significant. Metabolizable protein is derived from a combination of microbial protein and RUP (Sniffen et al., 1992). Predictions of microbial yield are directly related to ruminal CHO digestion (Russell et al., 1992). The prediction of microbial growth was most sensitive to components that affect the quantity and digestibility of $\mathrm{CHO}$ in the rumen (Figure 2C). In contrast, sensitivity in RUP prediction was most affected by $\mathrm{CP}$ concentration and the concentration of ADICP, which defines the indigestible protein fraction (Figure 2D).

Ruminal digestion of $\mathrm{CHO}$ and protein fractions in the CNCPS are calculated mechanistically according to the relationship originally proposed by Waldo et al. (1972), where digestion $=\mathrm{kd} /(\mathrm{kd}+\mathrm{kp})$, where $\mathrm{kp}$ is the rate of passage. Estimations of kd are, therefore, fundamental in predicting nutrient digestion and subsequent model outputs. With the exception of the CB3 kd (Table 2), which can be calculated according to Van Amburgh et al. (2003), kd values are not routinely estimated during laboratory analysis. Various techniques exist to estimate kd (Broderick et al., 1988, Nocek, 1988); however, technical challenges restrict their application in commercial laboratories and, thus, library values are generally relied on. Compared with variation in chemical components, predictions of ME were less sensitive to variation in $\mathrm{kd}$, and predictions of MP were more sensitive (Figure 3). Predictions of bacterial MP were most sensitive to the rate of starch digestion in both corn grain and corn silage (Figure 3C), whereas predictions of RUP were most sensitive to the PB1 kd in soybean meal, corn grain, and blood meal (Figure $3 \mathrm{D})$ which agrees with the findings of Lanzas et al. (2007a, 2007b). These data demonstrate the importance of kd estimates in the feed library, particularly for the prediction of MP. To improve MP prediction, methods that are practical for commercial laboratories to routinely estimate the $\mathrm{kd}$ of starch and protein fractions are urgently needed.

Overall, the prediction of ME-allowable milk was more sensitive to variation in the chemical composition compared with MP-allowable milk, which was more sensitive to variation in kd (Figure 4). Model sensitivity to variation in forage inputs was generally higher than concentrates, which can be attributed to the variation of the feed itself (Table 4), but also the higher inclusion of forage feeds in the reference diet (Table 7). The exception was corn grain, which despite having lower variability had a high inclusion that inflated the effect of its variance. Therefore, the components the model is most sensitive to are not static and will vary depend on the diet fed. Both variability and dietary inclusion should be considered when deciding on laboratory analyses to request for input into the CNCPS. Regular laboratory analyses of samples taken on-farm remains the recommended approach to characterizing the components in a ration and reduce the likely variance in the outputs.

\section{CONCLUSIONS}

Chemical components of feeds in the CNCPS feed library have been evaluated and refined using a multistep process designed to pool data from various sources and optimize feeds to be both internally consistent, and consistent with current laboratory data. When predicting ME, the model is most sensitive to variation in chemical composition, whereas MP predictions are more sensitive to variation in $\mathrm{kd}$. Methods that are practicable for commercial laboratories to routinely estimate the $\mathrm{kd}$ of starch and protein fraction are necessary to improve MP predictions. When using the CNCPS to formulate rations, the variation associated with environmental and management factors, both pre- and postharvest, should not be overlooked, as they can have marked effects on the composition of a feed. Regular laboratory analysis of samples taken on-farm, therefore, remains the recommended approach to characterizing the components in a ration. However, updates to CNCPS feed library provide a database of ingredients that are consistent with current laboratory data and can be used as a platform to both formulate rations and improve the biology within the model.

\section{ACKNOWLEDGMENTS}

The authors thank Cumberland Valley Analytical Services (Maugansville, MD) and Dairy One Cooperative (Ithaca, NY) for providing the feed chemistry data and Evonik Industries (Hanau, Germany) and Adisseo (Commentry, France) for providing the AA data. Financial support for R. J. Higgs was provided in partnership by DairyNZ (Hamilton, New Zealand) and Adisseo.

\section{REFERENCES}

Allred, M. C., and J. L. MacDonald. 1988. Determination of sulfur amino acids and tryptophan in foods and food and feed ingredients: collaborative study. J. Assoc. Off. Anal. Chem. 71:603-606.

AOAC International. 2005. Official Methods of Analysis of AOAC International. AOAC International, Gaithersburg, MD.

Armentano, L. E., S. J. Bertics, and G. A. Ducharme. 1997. Response of lactating cows to methionine or methionine plus lysine added to high protein diets based on alfalfa and heated soybeans. J. Dairy Sci. 80:1194-1199. 
Broderick, G. A. 1987. Determination of protein degradation rates using a rumen in vitro system containing inhibitors of microbial nitrogen metabolism. Br. J. Nutr. 58:463-475.

Broderick, G. A., R. J. Wallace, E. R. Ørskov, and L. Hansen. 1988. Comparison of estimates of ruminal protein degradation by in vitro and in situ methods. J. Anim. Sci. 66:1739-1745.

Chen, Z. H., G. A. Broderick, N. D. Luchini, B. K. Sloan, and E. Devillard. 2011. Effect of feeding different sources of rumen-protected methionine on milk production and N-utilization in lactating dairy cows. J. Dairy Sci. 94:1978-1988.

Choi, C. W., S. Ahvenjarvi, A. Vanhatalo, V. Toivonen, and P. Huhtanen. 2002. Quantitation of the flow of soluble non-ammonia nitrogen entering the omasal canal of dairy cows fed grass silage based diets. Anim. Feed Sci. Technol. 96:203-220.

Cottrell, W. 1999. Simplified program evaluation and review technique (PERT). J. Constr. Eng. Manage. 125:16-22.

Fox, D. G., L. O. Tedeschi, T. P. Tylutki, J. B. Russell, M. E. Van Amburgh, L. E. Chase, A. N. Pell, and T. R. Overton. 2004. The Cornell Net Carbohydrate and Protein System model for evaluating herd nutrition and nutrient excretion. Anim. Feed Sci. Technol. 112:29-78.

Givens, D. I., and H. Rulquin. 2004. Utilisation by ruminants of nitrogen compounds in silage-based diets. Anim. Feed Sci. Technol. 114:1-18.

Haefner, J. W. 2005. Modeling Biological Systems Principles and Applications. 2nd ed. Springer, New York, NY.

Hall, M. B. 2014. Selection of an empirical detection method for determination of water-soluble carbohydrates in feedstuffs for application in ruminant nutrition. Anim. Feed Sci. Technol. 198:28-37.

Hall, M. B. 2015. Determination of dietary starch in animal feeds and pet food by an enzymatic-colorimetric method: Collaborative study. J. AOAC Int. 98:397-409.

Hall, M. B., and D. R. Mertens. 2012. A ring test of in vitro neutral detergent fiber digestibility: Analytical variability and sample ranking. J. Dairy Sci. 95:1992-2003.

Higgs, R. J., L. E. Chase, and M. E. Van Amburgh. 2012. Development and evaluation of equations in the Cornell Net Carbohydrate and Protein System to predict nitrogen excretion in lactating dairy cows. J. Dairy Sci. 95:2004-2014.

Johnson, D. 1997. The triangular distribution as a proxy for the beta distribution in risk analysis. J. Royal Stat. Soc. 46:387-398. http://dx.doi.org/10.1111/1467-9884.00091.

Kertz, A. F. 1998. Variability in delivery of nutrients to lactating dairy cows. J. Dairy Sci. 81:3075-3084.

Krishnamoorthy, U., T. V. Muscato, C. J. Sniffen, and P. J. Van Soest. 1982. Nitrogen fractions in selected feedstuffs. J. Dairy Sci. $65: 217-225$

Landry, J., and S. Delhaye. 1992. Simplified procedure for the determination of tryptophan of foods and feedstuffs from barytic hydrolysis. J. Agric. Food Chem. 40:776-779.

Lanzas, C., C. J. Sniffen, S. Seo, L. O. Tedeschi, and D. G. Fox. 2007a. A revised CNCPS feed carbohydrate fractionation scheme for formulating rations for ruminants. Anim. Feed Sci. Technol. 136:167-190.

Lanzas, C., L. O. Tedeschi, S. Seo, and D. G. Fox. 2007b. Evaluation of protein fractionation systems used in formulating rations for dairy cattle. J. Dairy Sci. 90:507-521.

Law, A. M., and W. D. Kelton. 2000. Simulation Modeling and Analysis. 3rd ed. Tata McGraw-Hill Publishing Company, New Delhi, India.

Licitra, G., T. M. Hernandez, and P. J. Van Soest. 1996. Standardization of procedures for nitrogen fractionation of ruminant feeds. Anim. Feed Sci. Technol. 57:347-358.

Macgregor, C. A., C. J. Sniffen, and W. H. Hoover. 1978. Amino acid profiles of total and soluble protein in feedstuffs commonly fed to ruminants. J. Dairy Sci. 61:566-573.

Mertens, D. R. 2002. Gravimetric determination of amylase-treated neutral detergent fiber in feeds with refluxing in beakers or crucibles: collaborative study. J. AOAC Int. 85:1217-1240.

Muck, R. E. 1988. Factors influencing silage quality and their implications for management. J. Dairy Sci. 71:2992-3002.
Muscato, T. V., C. J. Sniffen, U. Krishnamoorthy, and P. J. Van Soest. 1983. Amino acid content of noncell and cell wall fractions in feedstuffs. J. Dairy Sci. 66:2198-2207.

Nocek, J. E. 1988. In situ and other methods to estimate ruminal protein and energy digestibility: A review. J. Dairy Sci. 71:20512069.

NRC. 2001. Nutrient Requirements of Dairy Cattle. 7th rev. ed. Natl. Acad. Press, Washington, DC.

O'Connor, J. D., C. J. Sniffen, D. G. Fox, and W. Chalupa. 1993. A net carbohydrate and protein system for evaluating cattle diets: IV. Predicting amino acid adequacy. J. Anim. Sci. 71:1298-1311.

Offner, A., A. Bach, and D. Sauvant. 2003. Quantitative review of in situ starch degradation in the rumen. Anim. Feed Sci. Technol. 106:81-93.

Offner, A., and D. Sauvant. 2004. Comparative evaluation of the Molly, CNCPS, and LES rumen models. Anim. Feed Sci. Technol. 112:107-130.

Pacheco, D., R. A. Patton, C. Parys, and H. Lapierre. 2012. Ability of commercially available dairy ration programs to predict duodenal flows of protein and essential amino acids in dairy cows. J. Dairy Sci. 95:937-963.

Palisade. 2010a. Guide to using @Risk version 5.7. Palisade Corporation, Ithaca, NY

Palisade. 2010b. Guide to using RISKOptimizer version 5.7. Palisade Corporation, Ithaca, NY.

Raffrenato, E. 2011. Physical, chemical and kinetic factors associated with fiber digestibility in ruminants and models describing these relationships. PhD Diss. Cornell University, Ithaca, NY.

Raffrenato, E., and M. Van Amburgh. 2011. Technical note: Improved methodology for analyses of acid detergent fiber and acid detergent lignin. J. Dairy Sci. 94:3613-3617.

Reynal, S. M., I. R. Ipharraguerre, M. Lineiro, A. F. Brito, G. A Broderick, and J. H. Clark. 2007. Omasal flow of soluble proteins, peptides, and free amino acids in dairy cows fed diets supplemented with proteins of varying ruminal degradabilities. J. Dairy Sci. 90:1887-1903.

Rulquin, H., and L. Delaby. 1997. Effects of the energy balance of dairy cows on lactational responses to rumen-protected methionine. J. Dairy Sci. 80:2513-2522.

Ruppel, K. A., R. E. Pitt, L. E. Chase, and D. M. Galton. 1995. Bunker silo management and its relationship to forage preservation on dairy farms. J. Dairy Sci. 78:141-153.

Russell, J. B., J. D. O'Connor, D. G. Fox, P. J. Van Soest, and C. J. Sniffen. 1992. A net carbohydrate and protein system for evaluating cattle diets: I. Ruminal fermentation. J. Anim. Sci. 70:35513561.

SAS Institute. 2010. JMP v7. SAS Institute Inc., Cary, NC.

Schwab, C. G. 1996. Rumen-protected amino acids for dairy cattle: Progress towards determining lysine and methionine requirements. Anim. Feed Sci. Technol. 59:87-101.

Schwab, C. G., C. K. Bozak, N. L. Whitehouse, and M. M. A. Mesbah. 1992. Amino acid limitation and flow to duodenum at four stages of lactation. 1. Sequence of lysine and methionine limitation. J. Dairy Sci. 75:3486-3502.

Shapiro, A. 2003. Monte Carlo sampling methods. Pages 353-425 in Handbooks in Operations Research and Management Science. Vol. 10. A. Ruszczynski and A. Shapiro, ed. Elsevier, Amsterdam, the Netherlands.

Siegfried, V. R., H. Ruckemmann, and G. Stumpf. 1984. Method for the determination of organic acids in silage by high performance liquid chromatography. Landwirtschaftliche Forschung 37:298 304

Sniffen, C. J., J. D. O'Connor, P. J. Van Soest, D. G. Fox, and J. B. Russell. 1992. A net carbohydrate and protein system for evaluating cattle diets: II. Carbohydrate and protein availability. J. Anim. Sci. 70:3562-3577.

Tedeschi, L. O., A. N. Pell, D. G. Fox, and C. R. Llames. 2001. The amino acid profiles of the whole plant and of four plant residues from temperate and tropical forages. J. Anim. Sci. 79:525-532.

Tylutki, T. P., D. G. Fox, V. M. Durbal, L. O. Tedeschi, J. B. Russell, M. E. Van Amburgh, T. R. Overton, L. E. Chase, and A. N. Pell. 
2008. Cornell Net Carbohydrate and Protein System: A model for precision feeding of dairy cattle. Anim. Feed Sci. Technol. 143:174-202

Van Amburgh, M. E., L. E. Chase, T. R. Overton, D. A. Ross, E. B. Recktenwald, R. J. Higgs, and T. P. Tylutki. 2010. Updates to the Cornell Net Carbohydrate and Protein System v6.1 and implications for ration formulation. Pages 144-159 in Proc. Cornell Nutr. Conf., Syracuse, NY. Cornell University, Ithaca, NY.

Van Amburgh, M. E., E. A. Colleo-Saenz, R. J. Higgs, D. A. Ross, E. B. Recktenwald, E. Raffrenato, L. E. Chase, T. R. Overton, J. K. Mills, and A. Foskolos. 2015. The Cornell Net Carbohydrate System: Updates to the model and evaluation of version 6.5. J. Dairy Sci. 98:6361-6380. http://dx.doi.org/10.3168/jds.2015-9378.

Van Amburgh, M. E., A. Foskolos, E. A. Collao-Saenz, R. J. Higgs, and D. A. Ross. 2013. Updating the CNCPS feed library with new amino acid profiles and efficiencies of use: Evaluation of model predictions - Version 6.5. Pages 59-76 in Proc. Cornell Nutr. Conf., Syracuse, NY. Cornell University, Ithaca, NY.

Van Amburgh, M. E., E. B. Recktenwald, D. A. Ross, T. R. Overton and L. E. Chase. 2007. Achieving better nitrogen efficiency in lactating dairy cattle: Updating field usable tools to improve nitrogen efficiency. Pages 25-38 in Proc. Cornell Nutr. Conf., Syracuse, NY. Cornell University, Ithaca, NY.

Van Amburgh, M. E., P. J. Van Soest, J. B. Robertson, and W. F. Knaus. 2003. Corn silage neutral detergent fiber: Refining a mathematical approach for in vitro rates of digestion. Pages 99-108 in Proc. Cornell Nutr. Conf., Syracuse, NY. Cornell University, Ithaca, NY.
Van Soest, P. J. 1994. Nutritional Ecology of the Ruminant. 2nd ed. Cornell University Press, Ithaca, NY.

Van Soest, P. J. 2015. The Detergent System of Analysis for Foods and Feeds. M. E. Van Amburgh, P. Uden, and P. Robinson, ed. Cornell University Publishing Services, Ithaca, NY.

Van Soest, P. J., and V. C. Mason. 1991. The influence of the maillard reaction upon the nutritive-value of fibrous feeds. Anim. Feed Sci. Technol. 32:45-53.

Van Soest, P. J., D. R. Mertens, and B. Deinum. 1978. Preharvest factors influencing quality of conserved forage. J. Anim. Sci. 47:712-720.

Velle, W., Ø. V. Sjaastad, A. Aulie, D. Grønset, K. Feigenwinter, and T. Framstad. 1997. Rumen escape and apparent degradation of amino acids after individual intraruminal administration to cows. J. Dairy Sci. 80:3325-3332.

Volden, H., W. Velle, O. M. Harstad, A. Aulie, and O. V. Sjaastad. 1998. Apparent ruminal degradation and rumen escape of lysine, methionine, and threonine administered intraruminally in mixtures to high-yielding cows. J. Anim. Sci. 76:1232-1240.

Waldo, D. R. L. W. Smith, and E. L. Cox. 1972. Model of cellulose disappearance from the rumen. J. Dairy Sci. 55:125-129.

Weiss, W. P. 1994. Estimation of digestibility of forages by laboratory methods. Pages 644-681 in Forage Quality, Evaluation, and Utilization. G. C. Fahey, ed. American Society of Agronomy, Crop Science Society of America, Soil Science Society of America, Madison, WI 